\title{
Diagnosing the average spatio-temporal impact of convective systems - Part 2: A model intercomparison using satellite data
}

\author{
M. S. Johnston ${ }^{1,2}$, S. Eliasson ${ }^{2,3}$, P. Eriksson ${ }^{1}$, R. M. Forbes ${ }^{4}$, A. Gettelman ${ }^{5}$, P. Räisänen ${ }^{6}$, and M. D. Zelinka ${ }^{7}$ \\ ${ }^{1}$ Department of Earth and Space Sciences, Chalmers University of Technology, Gothenburg, Sweden \\ ${ }^{2}$ Swedish Meteorological and Hydrological Institute, Norrköping, Sweden \\ ${ }^{3}$ Department of Computer Science, Electrical and Space Engineering, Division of Space Technology, Luleå University of \\ Technology, Kiruna, Sweden \\ ${ }^{4}$ European Centre for Medium-Range Weather Forecasts, Reading, UK \\ ${ }^{5}$ National Center for Atmospheric Research, Boulder, Colorado, USA \\ ${ }^{6}$ Finnish Meteorological Institute, Helsinki, Finland \\ ${ }^{7}$ Lawrence Livermore National Laboratory, Livermore, California, USA
}

Correspondence to: M. S. Johnston (shejo284@gmail.com)

Received: 12 March 2014 - Published in Atmos. Chem. Phys. Discuss.: 4 April 2014

Revised: 10 June 2014 - Accepted: 9 July 2014 - Published: 26 August 2014

\begin{abstract}
The representation of the effect of tropical deep convective (DC) systems on upper-tropospheric moist processes and outgoing longwave radiation is evaluated in the EC-Earth3, ECHAM6, and CAM5 (Community Atmosphere Model) climate models using satellite-retrieved data. A composite technique is applied to thousands of deep convective systems that are identified using local rain rate maxima in order to focus on the temporal evolution of the deep convective processes in the model and satellite-retrieved data.

The models tend to over-predict the occurrence of rain rates that are less than $\approx 3 \mathrm{~mm} \mathrm{~h}^{-1}$ compared to Tropical Rainfall Measurement Mission (TRMM) Multi-satellite Precipitation Analysis (TMPA). While the diurnal distribution of oceanic rain rate maxima in the models is similar to the satellite-retrieved data, the land-based maxima are out of phase.

Despite having a larger climatological mean uppertropospheric relative humidity, models closely capture the satellite-derived moistening of the upper troposphere following the peak rain rate in the deep convective systems. Simulated cloud fractions near the tropopause are larger than in the satellite data, but the ice water contents are smaller compared with the satellite-retrieved ice data. The models capture the evolution of ocean-based deep convective systems fairly well, but the land-based systems show significant discrepancies. Over land, the diurnal cycle of rain is too intense, with
\end{abstract}

deep convective systems occurring at the same position on subsequent days, while the satellite-retrieved data vary more in timing and geographical location.

Finally, simulated outgoing longwave radiation anomalies associated with deep convection are in reasonable agreement with the satellite data, as well as with each other. Given the fact that there are strong disagreements with, for example, cloud ice water content, and cloud fraction, between the models, this study supports the hypothesis that such agreement with satellite-retrieved data is achieved in the three models due to different representations of deep convection processes and compensating errors.

\section{Introduction}

Simulating moist convection has long been identified as critical if general circulation models (GCMs) are to reasonably represent key features of the tropical climate (Manabe and Strickler, 1964; Manabe and Wetherald, 1967). Cumulus convection occupies a wide range of time- and length scales and interacts with many atmospheric processes. Individual cumulus cloud sizes are much smaller than contemporary GCM grid resolution. These clouds can later grow into large organised clusters covering an area of $\sim 10^{3} \mathrm{~km}^{2}$. For a general review of tropical convection see Moncrieff et al. (2012). 
Deep convection is highly parameterised in climate GCMs, but numerical approximation of cumulus convection is a difficult problem (Emanuel, 1991; Arakawa, 2004; Gerard and Geleyn, 2005). Despite continuous improvements in convection parameterisation formulations and numerical advances, the representation of convection remains a major contributor to model uncertainty in climate simulations (Randall et al., 2003; Tost et al., 2006; Bechtold et al., 2008).

Previous studies of convective parameterisation in GCMs have examined the overall effect of deep convection on simulated atmospheric states and surface precipitation, but there have been few detailed studies of the evolution of the convective processes in a GCM, i.e. from initiation of convection to relaxation back to a mean atmospheric state. Tost et al. (2006) examined four different parameterisation schemes and found large differences in the participating models' precipitation patterns, even though the simulated humidity profiles were close to those derived from satellite data. Other studies have evaluated GCMs by looking at cloud feedback processes and precipitation connected with convective activity (e.g. Gehlot and Quaas, 2012; Nam et al., 2012).

The diurnal cycle of convection determines the timing of the variations in the upper-tropospheric water, which greatly affects the radiative balance and the surface precipitation in the region (Nesbitt and Zipser, 2003; Allan, 2011). This cycle of convection has long been a problem for GCMs. Del Genio and $\mathrm{Wu}$ (2010) used a cloud-resolving model to simulate the transition of land-based convection from shallow to deep. From inferred entrainment rates for convection of varying depths, they concluded that simple, non-adaptive formulations for convective entrainment contribute to the tendency of GCMs to transition too quickly from shallow to deep convection, thereby causing the peak in simulated rainfall to occur earlier than observed. Although this is a common problem in current GCMs, there has been some recent progress suggesting the potential to improve the representation of the diurnal cycle of convection in the future (Bechtold et al., 2013).

The abundance of passive and active satellite data in recent years allows for a more detailed look at the temporal evolution of the deep convective (DC) systems in climate models. Johnston et al. (2013) adapted the compositing method of Zelinka and Hartmann (2009) to diagnose and evaluate the spatio-temporal evolution of ocean-based DC systems, both from satellite-derived data and in the EC-Earth version 3 (EC-Earth3) GCM. The composite technique is able to reveal the evolution of the model-simulated DC systems at a high spatio-temporal resolution and thereby evaluate the model's ability to capture the response of upper-tropospheric moist processes to DC systems.

This current study presents a continuation of Johnston et al. (2013), which provides a novel application of the composite method with focus on an intercomparison of the spatio-temporal evolution of simulated DC systems of three GCMs: CAM5 (Community Atmosphere Model), ECHAM6, and EC-Earth3. These models all have different parameterisations of convection and moist processes, which greatly influences their representation, evolution, and impacts of deep convective systems. This study also looks at the evolution of these systems over both ocean and land regions. Similar to Johnston et al. (2013), the ultimate goal is to contribute to further development and improvement of GCMs.

Section 2 provides a brief description of the satellitederived data sources used in the evaluation as well as details of the three models used in the comparison. Section 3 describes the compositing technique that is the basis of this study. For a more in-depth discussion of the satellite data sets and the compositing methodology, the reader is referred to Part 1 of this study (see Johnston et al., 2013). Section 4 describes the results of the evaluation, and Sect. 5 provides a summary and conclusion.

\section{Data}

\subsection{Review of satellite data}

Satellite data for two full years (2007 and 2008) are used in this study. Surface hourly rain rates (RRs) are taken from the Tropical Rainfall Measurement Mission (TRMM) Multi-satellite Precipitation Analysis (TMPA) 3B42 version 6/6A data set. The TMPA data set is constructed using precipitation retrievals from a combination of geostationary, equatorial-orbiting, and polar-orbiting satellites that are scaled using surface rain gauge data (Huffman et al., 2007). Upper-tropospheric humidity (UTH) is provided by the Advanced Microwave Sounding Unit B (AMSU-B) and Microwave Humidity Sounder (MHS) onboard several satellites operated by the National Oceanic and Atmospheric Administration (NOAA) and the European Organisation for Exploration of Meteorological Satellites (EUMETSAT). This data set is described in Buehler and John (2005). Cloud fraction (CF) and ice water content (IWC) are provided by the CloudSat and Cloud-Aerosol Lidar and Infrared Pathfinder Satellite Observation (CALIPSO) Ice Cloud Property Product (2C-ICE) (Deng et al., 2012). Finally, outgoing longwave radiation (OLR) is obtained from the Cloud and Earth Radiant Energy System (CERES) sensors onboard the Aqua and Terra satellites. CERES data are taken from the Single Scanner Footprint (SSF) cloud edition 3A. Further details of satellite data sets used in the study are given in Johnston et al. (2013), and an overview is given in Table 1.

\subsection{Description of models}

Three GCMs participated in this study. The EC-Earth model (http://ecearth.knmi.nl) is described in Hazeleger et al. (2010). In this study we use version 3, in which the atmospheric component is the Integrated Forecast System (IFS Cycle 36r4). This cycle is closely aligned with the seasonal forecasting system of the European Centre for MediumRange Weather Forecasts (ECMWF). As such, EC-Earth3 
Table 1. List of the satellite data sets used in this study along with their acronyms, horizontal resolutions, and the version of the data set.

\begin{tabular}{lllc}
\hline Variable & Source & Resolution & Version \\
\hline Rain rate $(\mathrm{RR})\left[\mathrm{mm} \mathrm{h}^{-1}\right]$ & TMPA & $\approx 25 \mathrm{~km}$ & $6 / 6 \mathrm{~A}$ \\
Upper-tropospheric humidity $(\mathrm{UTH})\left[\% \mathrm{RH}_{i}\right]$ & AMSU-B & $\approx 16 \mathrm{~km}$ & - \\
Cloud fraction $(\mathrm{CF})[\%]$ & $2 \mathrm{C}-\mathrm{ICE}$ & $\approx 2 \mathrm{~km}$ & - \\
Cloud ice water content $(\mathrm{IWC})\left[\mathrm{mg} \mathrm{m}^{-3}\right]$ & $2 \mathrm{C}-\mathrm{ICE}$ & $\approx 2 \mathrm{~km}$ & - \\
Outgoing longwave radiation $(\mathrm{OLR})\left[\mathrm{W} \mathrm{m}^{2}\right]$ & CERES & $\approx 20 \mathrm{~km}$ & $3 \mathrm{~A}$ \\
\hline
\end{tabular}

shares the advances made in Numerical Weather Prediction from ECMWF. Technical details about IFS can be found at http://www.ecmwf.int/research/ifsdocs. The National Center for Atmospheric Research Community Atmospheric Model is a prominent model within the climate modelling community and is the atmospheric component of several climate models around the world. Version 5 (CAM5) is described in Neale et al. (2012), and more technical details about the model can be found at http://www.cesm.ucar.edu/ models/cesm1.0/cam/. The final model is the sixth generation of the Max Planck Institute for Meteorology's atmospheric model, ECHAM6. An overview of this model is given in Stevens et al. (2013), and more technical details can be found online (http://www.mpimet.mpg.de/fileadmin/publikationen/ Reports/WEB_BzE_135.pdf).

Our interest here lies in the performance of the atmospheric models, rather than the coupled atmosphereocean system, and therefore the model setup follows mainly the configuration stipulated by the Atmospheric Model Intercomparison Project (AMIP, http:/www-pcmdi.llnl.gov/ projects/amip). Hence, the sea surface temperatures (SST) and sea ice fields were prescribed. EC-Earth3 used ERAInterim SST and sea ice data, while CAM5 and ECHAM6 used standard AMIP2 SST and sea ice files, which are based on a merged product of monthly mean Hadley Centre Sea Ice and SST data set version 1 (HadISST1) and version 2 of the National Oceanic and Atmospheric Administration weekly optimum interpolation SST analysis (Hurrell et al., 2008). Default model setup was used in the experiments, except that for ECHAM6 the time interval between full radiation calculations was $1 \mathrm{~h}$ rather than $2 \mathrm{~h}$ as specified in Stevens et al. (2013). All the models were run for at least 1 year prior to 2007 to avoid spin-up issues. Some basic specifications about each model are listed in Table 2.

Three-hourly model data are used in this study. The model results are analysed for the same period as the satellite data (2007-2008). For CAM5 and ECHAM6, output variables are stored as 3-hourly averages, but EC-Earth3's variables include both accumulated and instantaneous fields. The accumulated variables are converted to mean values by dividing by the sum of the time steps between each output. The instantaneous variables are interpolated to the centre of the time steps in order to match the accumulated variables. The number of vertical levels differs between the models (see Table 2) and - when compositing the UTH, IWC, and layered CF each of these outputs is interpolated to constant pressure levels ranging from 500 to $100 \mathrm{hPa}$ at $50 \mathrm{hPa}$ intervals. Also, the UTH is defined as the mean relative humidity with respect to ice between 500 and $200 \mathrm{hPa}$.

The reader needs to bear in mind that model output can be defined very differently from the corresponding satellite data. The satellite-derived CF and IWC, using radar reflectivity and lidar backscatter, are sensitive to a range of ice particle sizes associated with cloud ice and precipitating snow for all parts of a deep convective system (including the stratiform anvil and convective core). In contrast, the models have distinct representations of different parts of a deep convective system, which differ between each model and are not all generally available as part of a standard output. All three models have separate categories for stratiform cloud ice, stratiform precipitating snow, and convective precipitating snow. However, only the stratiform cloud ice was available as a standard product from all of the three. As stratiform cloud ice represents the dominant contribution to IWC in the upper troposphere, it is valid to compare with the satellite-derived IWC in this study. However, lower in the atmosphere, the precipitating snow IWC becomes more significant and care must be taken in any conclusion drawn from the comparison. Cloud fraction is represented differently in the models, as a prognostic variable in EC-Earth3 and diagnostically in ECHAM6 and CAM5. The "cloudy" fraction associated with stratiform and convective precipitating snow, which is included in the satellite-derived $\mathrm{CF}$, is not included in the model definition of CF. Again, this has little impact in the upper troposphere, which is dominated by the ice cloud and is the focus of this study, but it does have more of an impact at lower altitudes where the precipitating snow becomes more important.

\section{Method}

\subsection{Composite}

The methodology used to compile the results in the form presented is described in detail in Johnston et al. (2013). We have largely continued with this method, with the exception that the data are instead interpolated to a common $1^{\circ}$ spatial resolution. Selection of the systems is based on local RR maxima taken from rates exceeding the 90th percentile of the 
Table 2. Some basic information about each model.

\begin{tabular}{|c|c|c|c|c|c|}
\hline Model & Native grid & Levels & Top of model & Convection scheme & Cloud scheme \\
\hline CAM5 & $0.94^{\circ} \times 1.25^{\circ}$ & 30 & $10 \mathrm{hPa}$ & Zhang and McFarlane (1995) & $\begin{array}{l}\text { Gettelman et al. (2008); } \\
\text { Morrison and Gettelman (2008) }\end{array}$ \\
\hline EC-Earth3 & $0.70^{\circ} \times 0.70^{\circ}$ & 91 & $0.1 \mathrm{hPa}$ & $\begin{array}{l}\text { Tiedtke (1989); } \\
\text { Bechtold et al. }(2004,2008)\end{array}$ & $\begin{array}{l}\text { Tiedtke (1993); } \\
\text { Forbes et al. (2011) }\end{array}$ \\
\hline ECHAM6 & $0.90^{\circ} \times 0.90^{\circ}$ & 95 & $0.01 \mathrm{hPa}$ & $\begin{array}{l}\text { Tiedtke (1989); } \\
\text { Nordeng (1994) }\end{array}$ & $\begin{array}{l}\text { Sundqvist et al. (1989); } \\
\text { Lohmann and Roeckner (1996) }\end{array}$ \\
\hline
\end{tabular}

total RRs ( $>0$ ) within $\pm 30^{\circ}$ latitude. For TMPA, EC-Earth3, ECHAM6, and CAM5, the 90th-percentile RR thresholds are approximately $1.5,0.5,0.3$, and $0.5 \mathrm{~mm} \mathrm{~h}^{-1}$ respectively.

An alternative technique for the compositing would be to use the same RR threshold for all data sets. It would seem reasonable to assume that systems with larger RRs have, on average, larger effects on related variables such as UTH, CF, and IWC. However, upon further examination, the results of the composite analysis proved not to be very sensitive to the choice of the RR threshold. Specifically, when the TMPA threshold of $1.5 \mathrm{~mm} \mathrm{~h}^{-1}$ was also used for the models, the evolution of the modelled convective systems did not differ appreciably from that seen for the model-specific thresholds mentioned above. However, the use of a RR threshold of $1.5 \mathrm{~mm} \mathrm{~h}^{-1}$ reduced the sample size for EC-Earth 3 and ECHAM by up to $\sim 60 \%$, and for CAM5 by up to $\sim 90 \%$ for some regions. In the interest of keeping the sample sizes equally large for all data sets, and also to be consistent with Part 1, we employ the data-set-specific RR thresholds in this study.

\subsection{Regions}

The study looks at the statistical effect of DC systems on upper-tropospheric moist processes over several regions across the tropics. A separation between land- and oceanbased systems is made, as these differ in certain characteristics, such as their diurnal cycle. The regions depicted in Fig. 1 are selected such that a strict separation between DC systems in the different regions is maintained. The results have been analysed within each region (not shown), but, since there are no major differences between the different regions of similar surface types, all systems over ocean and land regions are merged by taking the mean, weighted by the number of DC systems per region.

\section{Results}

\subsection{Precipitation}

The use of surface precipitation as a proxy for identifying DC systems at peak convection necessitates a brief investigation of this aspect of the models. We focus on the normalised probability density function of RRs and the diurnal

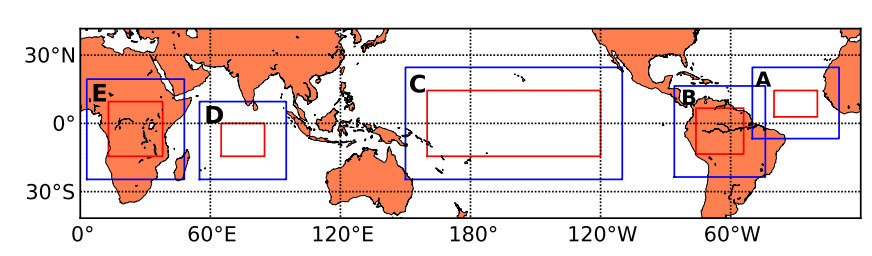

Figure 1. Selected regions of deep convection across the tropics: central Atlantic (A), the Amazon Basin (B), Pacific Ocean (C), Indian Ocean (D), and central Africa (E). Ocean-based regions are the combination of D, C, and A; land-based regions are E and B. Red areas represent DC system centre regions, while blue boxes are data sampling regions.

cycle (i.e. the relative occurrence of DC systems per local solar time (LST)).

\subsubsection{Rain rate statistics}

Table 3 shows the area-weighted mean RR over each region given in Fig. 1 and the combined ocean and land areas. The models tend to produce fairly similar RRs to TMPA and to each other over the areas examined. However, the mean precipitation is systematically overestimated in the models compared to TMPA. Over ocean areas, modelled precipitation can be up to $\approx 30 \%$ higher, while over land areas the models are closer to the satellite-derived data. A part of this bias lies in uncertainties in the TMPA data, which, due to a lack of sensitivity in the AMSU-B to low precipitation rates over ocean areas, underestimate low RRs (Huffman et al., 2007).

The probability distribution of RRs for ocean and land regions is shown in Fig. 2. Over both ocean and land, the models overestimate the frequency of occurrence of RRs $<3 \mathrm{~mm} \mathrm{~h}^{-1}$ and underestimate the frequency of occurrence of RRs $>3 \mathrm{~mm} \mathrm{~h}^{-1}$ relative to TMPA. This tendency of excessive light precipitation has been noted previously (e.g. Tost et al. (2006) and Stephens et al. (2010)). Simulated RRs above $10 \mathrm{~mm} \mathrm{~h}^{-1}$ are more common over ocean than over land.

\subsubsection{Diurnal distribution of DC systems}

Figure 3 illustrates the diurnal cycle of the DC systems analysed in this study. The figure shows the relative frequency 
Table 3. Area-weighted mean RR $\left[\mathrm{mm} \mathrm{h}^{-1}\right.$ ] for the regions depicted in Fig. 1 plus those of the merged ocean and land regions. All data are interpolated to a $1^{\circ}$ grid.

\begin{tabular}{lccccccc}
\hline Source & Atlantic & Indian & Pacific & Amazon & Africa & Ocean & Land \\
\hline TMPA & 0.12 & 0.17 & 0.13 & 0.16 & 0.09 & 0.14 & 0.12 \\
EC-Earth3 & 0.15 & 0.20 & 0.17 & 0.19 & 0.10 & 0.17 & 0.14 \\
ECHAM6 & 0.14 & 0.22 & 0.19 & 0.19 & 0.10 & 0.19 & 0.14 \\
CAM5 & 0.14 & 0.21 & 0.18 & 0.19 & 0.12 & 0.18 & 0.16 \\
\hline
\end{tabular}
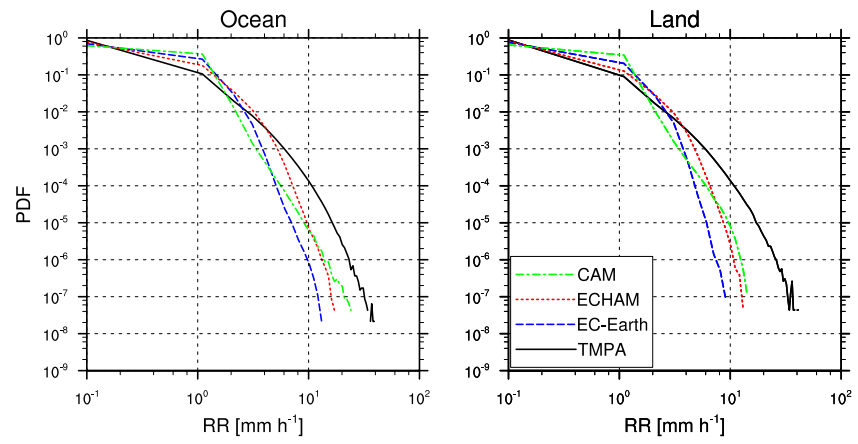

Figure 2. Normalised probability density function of surface rain rates for ocean-based (left plot) and land-based (right plot) regions for total precipitation of the merged regions described in Fig. 1.

of occurrence of the DC systems as a function of local solar time.

For ocean-based systems, the relative occurrence of TMPA DC systems exhibits a peak from midnight to early morning and a maximum centred around 05:00 LST. A relatively higher frequency of DC system occurrence persists into the afternoon. For ocean-based systems, there is broad spread in the diurnal distribution of RRs above $10.0 \mathrm{~mm} \mathrm{~h}^{-1}$, but with a minimum occurrence in the afternoon to early evening. Another notable feature of TMPA is the higher frequency of intense land-based DC systems around midnight. Similar findings were reported by Hendon and Woodberry (1993) and Eriksson et al. (2010), who found significant diurnal amplitude of deep convection over land but a weaker cycle over ocean. Over land regions convection begins in the afternoon and culminates in the late evening before tapering off after midnight.

The models' ocean-based DC systems show a tendency for deep convection after midnight with a drop in the frequency of occurrence in the afternoon to early evening. This is in very good agreement with TMPA. While the relative occurrence of DC systems in ECHAM6 and EC-Earth3 is of the same order as TMPA for DC systems with a RR between 1.5 and $4.0 \mathrm{~mm} \mathrm{~h}^{-1}$, CAM5 tends to show a somewhat higher frequency after midnight.

Over land, there is a larger disagreement with TMPA. All the models place the bulk of the convective activity roughly between 10:00 and 17:00 LST, which is earlier than TMPA.
This tendency for land-based convection to occur too early in the day, when the solar heating is greatest, is a well-known bias in models (e.g. Del Genio and Wu, 2010).

\subsection{Composites}

This section discusses the composites of the RR, UTH, CF, IWC, and OLR. Sub-sections are dedicated to each variable and discuss ocean- and land-based DC systems. The reader is reminded that the composites are weighted averages of the land- and ocean-based regions, as well as averages of thousands of DC systems. In addition the term "peak convection" refers to the $0 \mathrm{~h}$ of the composite, and in places where the spatial mean of the composite is averaged temporally it is simply referred to as the spatio-temporal mean.

\subsubsection{Rain rate}

Figure 4 depicts the RR composite for ocean- and land-based systems for both TMPA and models results.

For ocean-based systems, TMPA shows an east-west band of precipitation throughout the time period, which is very symmetrical around $0 \mathrm{~h}$ and indicates a predominantly zonal movement of these DC systems. An area of larger RRs that is present in the eastern part of the domain at $-18 \mathrm{~h}$ steadily strengthens while propagating westward, reaches a maximum value at the centre of the domain at $0 \mathrm{~h}$, and then steadily weakens as it continues to move westward.

The models represent the evolution of the RRs over ocean in a very similar manner to TMPA. EC-Earth3 shows the shortest period of elevated RRs, which indicates a shorter convective precipitation process. ECHAM6 and CAM5 are closer to TMPA, although ECHAM6's region of elevated RR extends over a broader area than that of CAM5 and TMPA.

For land-based DC systems derived from TMPA, the RR distribution pattern across the domain is more circular than zonally elongated. This circular pattern suggests that these DC systems could have both zonal and meridional motions. From about -18 to $-9 \mathrm{~h}$, there is a distinct minimum near the domain centre. As time progresses, a RR maximum, originally located to the east of the domain centre, strengthens and moves towards the domain centre. The strengthening of RRs before peak convection and their decay afterwards appear to have very similar duration. Towards the end of the composite 

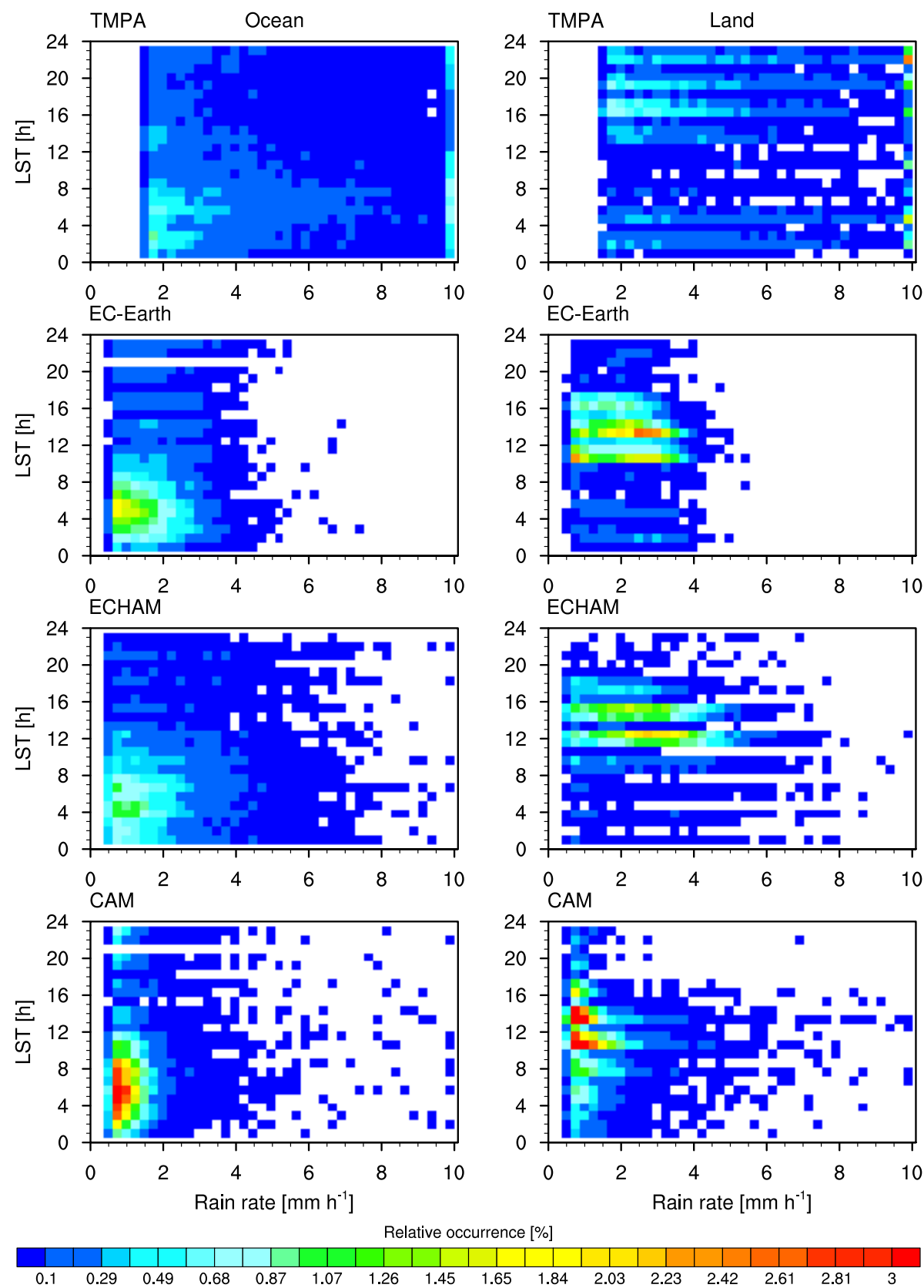

Figure 3. Relative occurrence of selected DC systems as a function of rain rate (RR) and the local solar time (LST) of peak convection (i.e. the timing of " $0 \mathrm{~h}$ " in the composite analysis). The results are given for Tropical Rainfall Measuring Mission Multi-satellite Precipitation Analysis (TMPA), EC-Earth3, ECHAM6, and CAM5. The RR bin size is set to $0.25 \mathrm{~mm} \mathrm{~h}^{-1}$ and $1 \mathrm{~h}$. The empty space for the lowest RR reflects the respective threshold values for the DC systems. The TMPA RRs above $10.0 \mathrm{~mm} \mathrm{~h}^{-1}$ are mapped to $10.0 \mathrm{~mm} \mathrm{~h}-1$ to reduce the spread of the data along the $x$ axis.

time period, another minimum appears at the spatial centre, similar to what occurred at the beginning of the time period.

Compared to their ocean-based counterparts, the models' land-based DC systems are markedly different in the composite. Notably, the growth and decay of the intense RR region over land occurs over a shorter timescale in the models. This behaviour is apparent especially for EC-Earth3 and ECHAM6. The spatial signature of the DC systems in ECHAM6 is significantly broader than in the other models and in TMPA. ECHAM6 and EC-Earth3 also capture the minimum in RR at the centre of the domain before and after the main DC event, as seen in TMPA. Also, these models are able to capture the circular patterns seen in the TMPA landbased systems. In general, simulated RRs are, on average, 


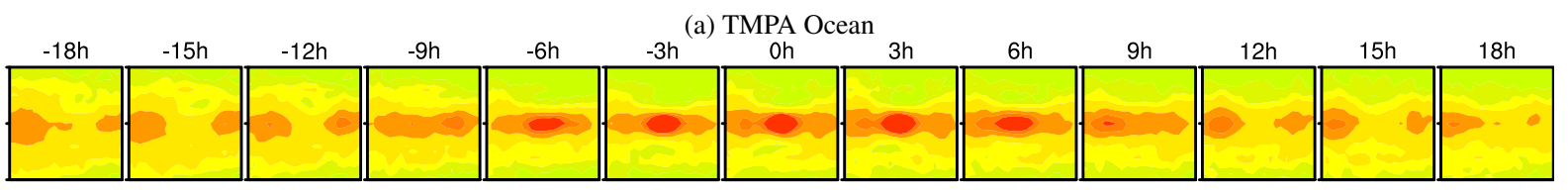

(b) EC-Earth3 Ocean

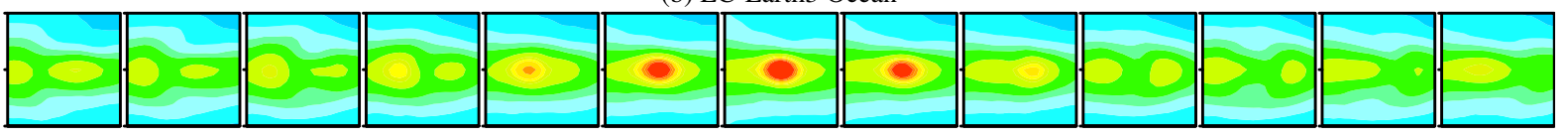

(c) ECHAM6 Ocean

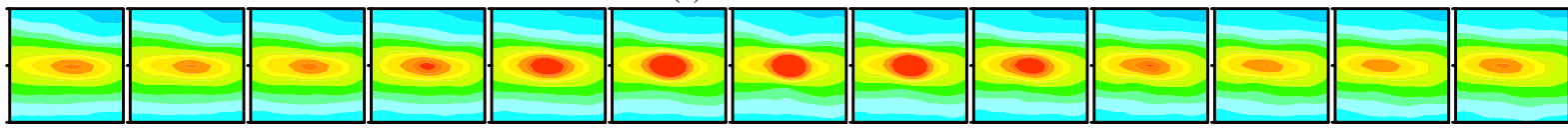

(d) CAM5 Ocean

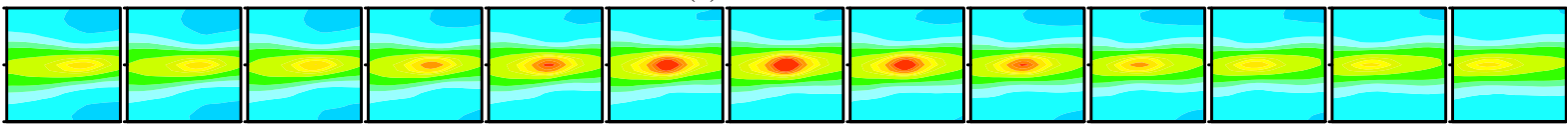

(e) TMPA Land

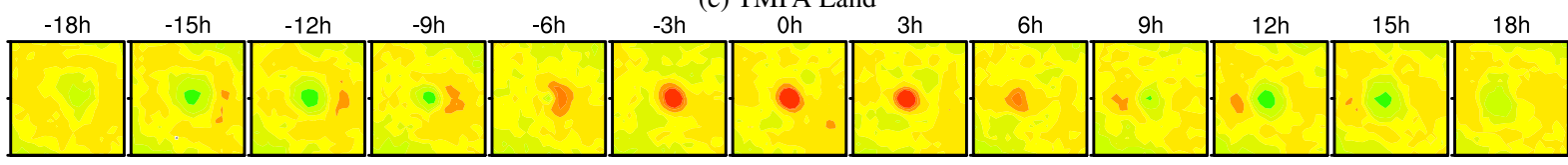

(f) EC-Earth3 Land

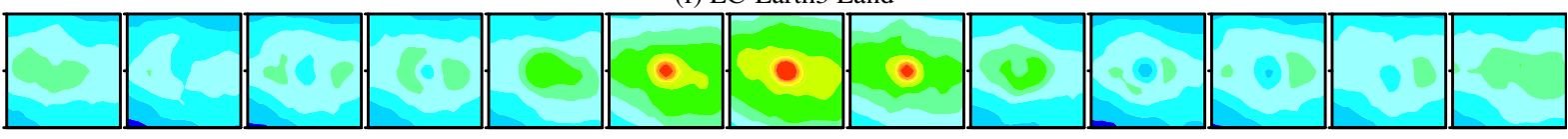

(g) ECHAM6 Land

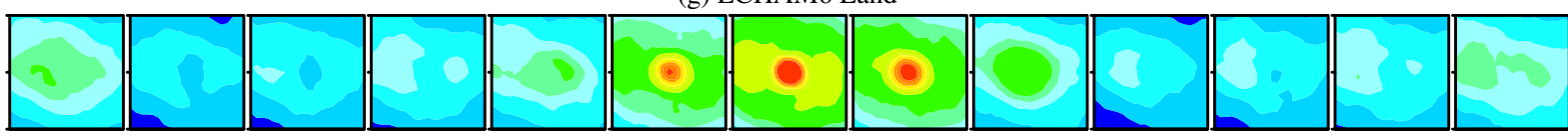

(h) CAM5 Land
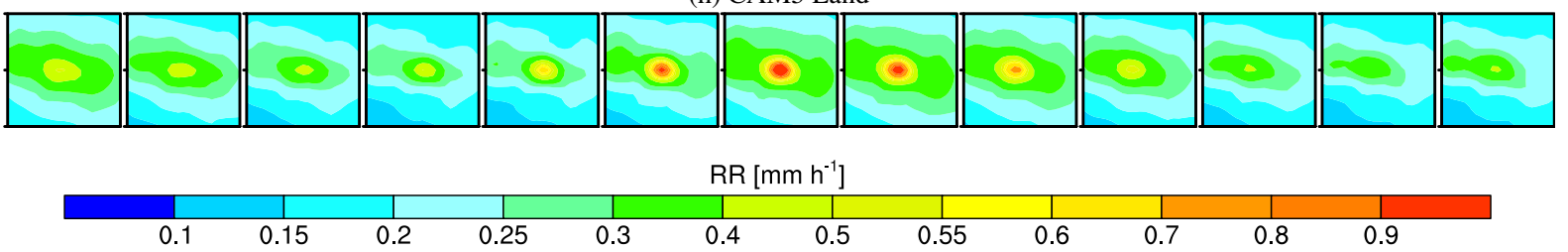

Figure 4. Composite of rain rate for ocean-based (a-d) and land-based (e-h) systems for the Tropical Rainfall Measuring Mission Multisatellite Precipitation Analysis (TMPA) followed by the models. The spatio-temporal coverage of $\pm 18 \mathrm{~h}$ at every $3 \mathrm{~h}$ interval and $\pm 10^{\circ}$ longitude and latitude is taken from the centre point and graduated every $\pm 1^{\circ}$.

comparable in magnitude to TMPA close to the centre of the DC systems, but are weaker away from the centre of the domain.

\subsubsection{Upper-tropospheric humidity}

Figure 5 shows the composite UTH for ocean- and landbased DC systems for the models and AMSU. AMSU over ocean areas shows a broad band of elevated humidity across most of the domain and throughout the period. However, a very focused region of humidity exceeding $60 \%$ is apparent at $-6 \mathrm{~h}$. This feature increases in spatial coverage and magnitude until about $6 \mathrm{~h}$, when a maximum is reached. Afterwards, there is a notable reduction in the moisture level at the domain centre that continues beyond $18 \mathrm{~h}$, in addition to a spreading-out horizontally towards the domain boundaries. The latitudinal distribution pattern varies from region 


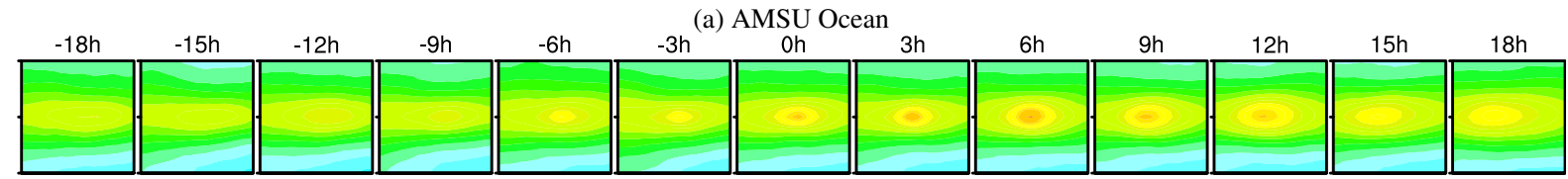

(b) EC-Earth3 Ocean

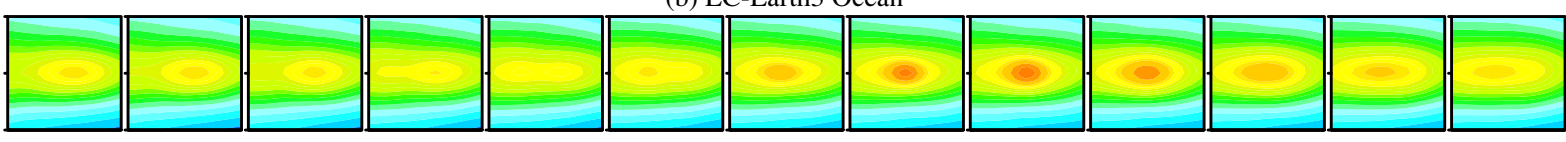

(c) ECHAM6 Ocean

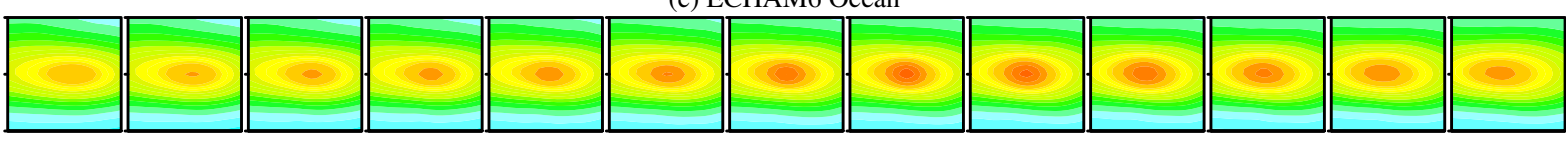

(d) CAM5 Ocean

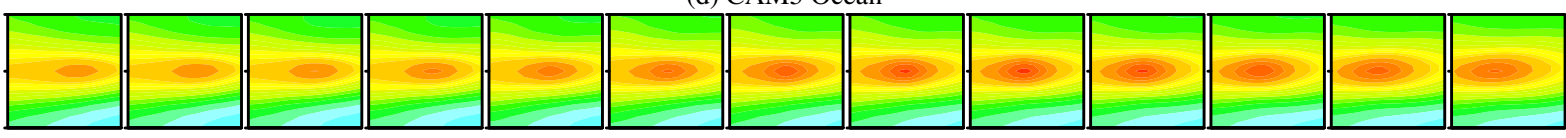

(e) AMSU Land

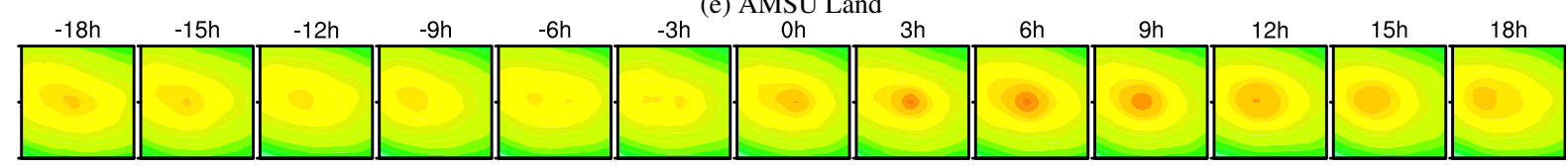

(f) EC-Earth3 Land

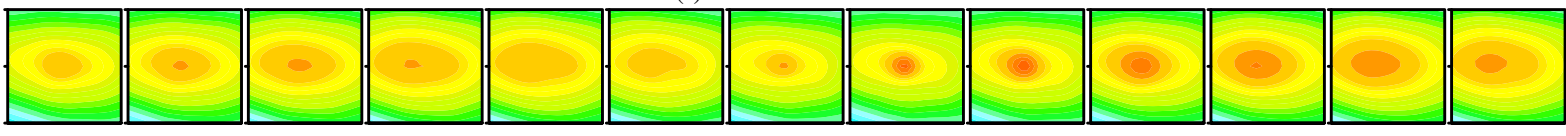

(g) ECHAM6 Land

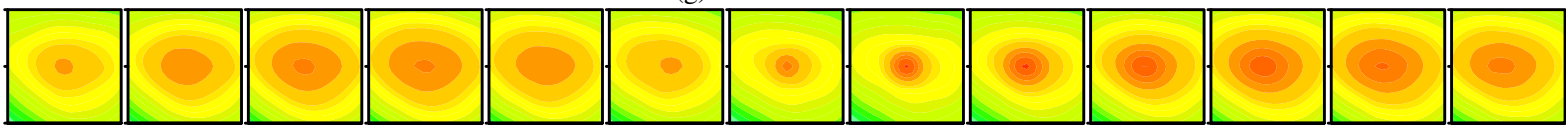

(h) CAM5 Land
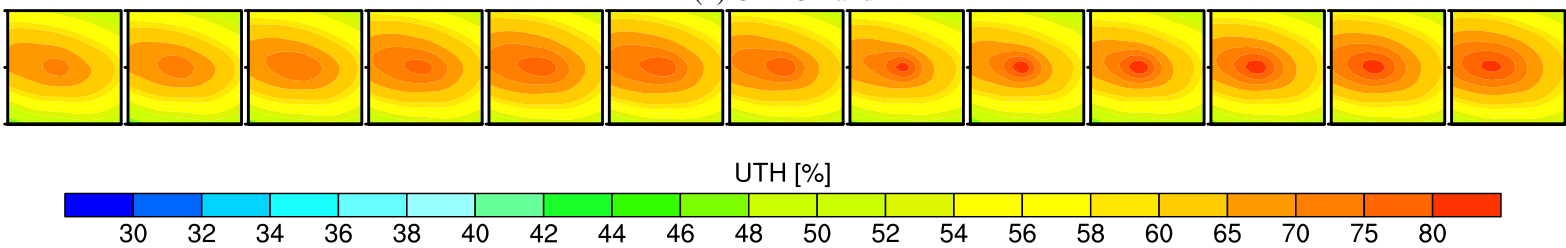

Figure 5. Composite of upper-tropospheric humidity (UTH) for ocean-based (a-d) and land-based (e-h) systems for Advanced Microwave Sounding Unit (AMSU) followed by the models. The spatio-temporal coverage of $\pm 18 \mathrm{~h}$ at every $3 \mathrm{~h}$ interval and $\pm 10^{\circ}$ longitude and latitude is taken from the centre point and graduated every $\pm 1^{\circ}$.

to region, but the resulting composite indicates that drier areas are generally found to the south of the DC systems.

The models' representations of the effect of ocean-based DC systems on the UTH seem to capture the development and dissipation of the systems. However, the models, especially CAM5, tend to show a moister upper troposphere. The spatio-temporal mean UTHs are $\sim 44 \%$ for EC-Earth3, $\sim 47 \%$ for ECHAM6, and $\sim 50 \%$ for CAM5, compared with $\sim 44 \%$ in AMSU. However, the maximum
UTH across the domain for all models can, locally, increase to $\sim 80 \%$, which is about 10 to 20 percentage points higher than AMSU. EC-Earth3 exhibits a much moister upper troposphere following convection than preceding it, which is rather similar to AMSU. For ECHAM6 and CAM5, UTH remains high throughout the composites and also exhibits less obvious temporal asymmetries.

The AMSU UTH pattern is quite different over land compared to those over ocean. While the oceanic systems are 
more zonally elongated, the land-based systems are more axisymmetric. The spatio-temporal mean UTH for these systems is $\sim 52 \%$, but moisture from DC systems can locally elevate the UTH to over $72 \%$. There is a clear reduction in UTH from -18 to $-6 \mathrm{~h}$ followed by rapid increase at the domain centre from time bins -3 to $6 \mathrm{~h}$. This reduction in moisture early in the composite could be explained by the dissipation of earlier convection.

For the land-based systems the models' spatio-temporal mean UTHs are $\sim 51 \%$ for EC-Earth3, $\sim 57 \%$ for ECHAM6, and $\sim 61 \%$ for CAM5. These values are not only significantly higher than those over ocean areas, but large values are also found throughout most of the domain, which is in agreement with AMSU. However, ECHAM6 and CAM5 show significantly higher levels of humidity than AMSU over the entire composite domain, with EC-Earth3 being closest to AMSU. While AMSU shows a region of slightly elevated humidity early in the composite sequence, the models indicate much higher UTH values at this juncture.

\subsubsection{Cloud fraction}

Figure 6 shows the composite average $\mathrm{CF}$ at $200 \mathrm{hPa}$ for $2 \mathrm{C}$ ICE and the models. CF is defined using the 2C-ICE data set where IWC is $>0$; thus areas of precipitation will also be counted as CF. This must be taken into consideration when interpreting the results.

For the 2C-ICE-derived ocean-based systems, the mean $\mathrm{CF}$ of the domain is of the order of $22 \%$. There is an increased $\mathrm{CF}$ at the domain centre from about -9 to $9 \mathrm{~h}$. Also, close to the domain centre, the spatial mean CF can exceed $70 \%$.

The models' ocean-based systems show mean CFs across the domain that are slightly larger than 2C-ICE: $\sim 28 \%$ for EC-Earth3, $\sim 29 \%$ for ECHAM6, and $\sim 31 \%$ for CAM5. Generally, CAM5 shows the largest CF across the domain and throughout the composite time period. Elevated levels of $\mathrm{CF}$ at the domain centre can be seen in EC-Earth3 from about 0 to $12 \mathrm{~h}$, but in ECHAM6 and CAM5 this pattern is not as easily discerned.

The 2C-ICE land-based systems show a mean CF that is higher than for ocean-based systems by about 8 percentage points, and, locally, the $\mathrm{CF}$ can reach up to $80 \%$. The $2 \mathrm{C}$ ICE-derived CF remains anomalously large for about $9 \mathrm{~h}$ following convection, and is largest at $3 \mathrm{~h}$. Both the models and 2C-ICE place the spatial maximum CF (70-80\%) between 3 and $6 \mathrm{~h}$, but as time progresses the high $\mathrm{CF}$ at the domain centre spreads out across the domain until about 15-18 h.

Consistent with the results of the simulated UTH over land, more cloudiness is generated for simulated land-based DC systems. The spatio-temporal mean CFs in CAM5 and EC-Earth 3 are higher by about 13 and 6 percentage points respectively. ECHAM6, however, shows only an increase of less than 1 percentage point. Again, the models, between themselves, show similar CF maxima attained within the do- main of $\sim 78 \%$. Similar to the UTH, the spatial patterns of the simulated CFs are broader over land and display a somewhat axial symmetry with respect to the domain centre. For these systems, the models show a similar pattern of decreased $\mathrm{CF}$ as time approaches peak convection, before increasing again between 0 and $18 \mathrm{~h}$. However, ECHAM6 shows a much faster reduction in $\mathrm{CF}$ by $15 \mathrm{~h}$ than the other two models.

\subsubsection{CF time-altitude anomaly}

Figure 7 illustrates the $\mathrm{CF}$ anomalies as a function of both pressure and time. In this figure, the time bins span $\pm 48 \mathrm{~h}$, and the data are averaged over $\pm 3^{\circ}$ latitude, $\pm 10^{\circ}$ longitude, from the domain centre point in order to better focus on the DC systems' core region. The anomaly is derived by subtracting the background state, which is taken as the average of the time bins -48 to $-39 \mathrm{~h}$. Because $2 \mathrm{C}$-ICE (both CF and IWC) tend to be noisy, the spatio-temporal pattern of the anomaly in the figure emerges only after applying a $12 \mathrm{~h}$ running average. Such smoothing does not have a significant effect on the models but has been applied for consistency (valid also for Fig. 9 in the following section).

Over ocean regions, the 2C-ICE CF anomaly associated with DC is vertically coherent, with CF increasing by about 10 percentage points between -6 and $12 \mathrm{~h}$ at all levels. A maximum CF anomaly of about 12 percentage points covers a region between 250 and $150 \mathrm{hPa}$ between peak convection and $10 \mathrm{~h}$. A secondary positive $\mathrm{CF}$ anomaly, which is not fully separate from the one at peak convection, appears at $\sim 21 \mathrm{~h}$. In addition, a series of positive CF anomalies is seen in the uppermost troposphere $(\sim 100-150 \mathrm{hPa})$ $24 \mathrm{~h}$ apart centred at $\sim-27,-3,21$, and $45 \mathrm{~h}$. A contributor to the anomaly's vertically uniform structure is the larger precipitating hydrometeors being included in the definition of the cloud fraction.

The modelled CF anomalies for ocean-based systems vary greatly among themselves and look quite different from 2C-ICE. The greatest concordance between the models and 2C-ICE occurs between 300 and $100 \mathrm{hPa}$. Elsewhere, there are major differences. For EC-Earth3, the anomaly at pressure levels $>300 \mathrm{hPa}$ is significantly lower than 2C-ICE. This disparity can partly be explained by the lack of a precipitating component in the simulated CFs. ECHAM6 and CAM5 anomalies show similar magnitudes as 2C-ICE, but are sustained over a much longer duration at pressure levels $>300 \mathrm{hPa}$. The CAM5 anomalies at peak convection and $24 \mathrm{~h}$ seem to merge, suggesting a repetition of DC systems that causes the CF anomaly to persist for twice as long as $2 \mathrm{C}-\mathrm{ICE}$. Evidence of the models' diurnal cycle of convection can be seen in the ocean-based systems around $-24,24$, and $48 \mathrm{~h}$.

For land regions, the 2C-ICE CF anomaly is weaker and of shorter duration than for ocean-based systems. The largest $\mathrm{CF}$ anomaly is located near $200 \mathrm{hPa}$ between 0 and $12 \mathrm{~h}$, and it persists for a much shorter time, $\approx 12$ versus $\sim 20 \mathrm{~h}$ 


\begin{tabular}{|c|c|c|c|c|c|c|c|c|c|c|c|c|}
\hline \multicolumn{13}{|c|}{ (a) 2C-ICE Ocean } \\
\hline$-18 \mathrm{~h}$ & $-15 h$ & $-12 h$ & $-9 h$ & $-6 \mathrm{~h}$ & $-3 h$ & $0 \mathrm{~h}$ & $3 \mathrm{~h}$ & $6 \mathrm{~h}$ & $9 \mathrm{~h}$ & $12 \mathrm{~h}$ & $15 \mathrm{~h}$ & $18 \mathrm{~h}$ \\
\hline 989 & 28 & $\sqrt{105}$ & 81 & $\sqrt{104}$ & $\sqrt{9 \times 96}$ & $\sqrt{98}$ & 98 & $4, \sqrt{1}$ & 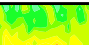 & $\sqrt{1+26 x}$ & & \\
\hline
\end{tabular}

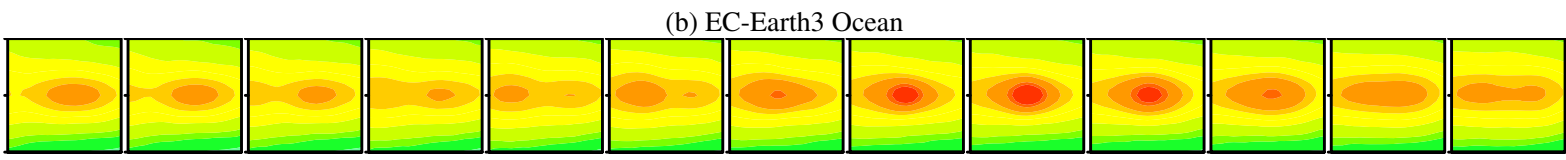

(c) ECHAM6 Ocean

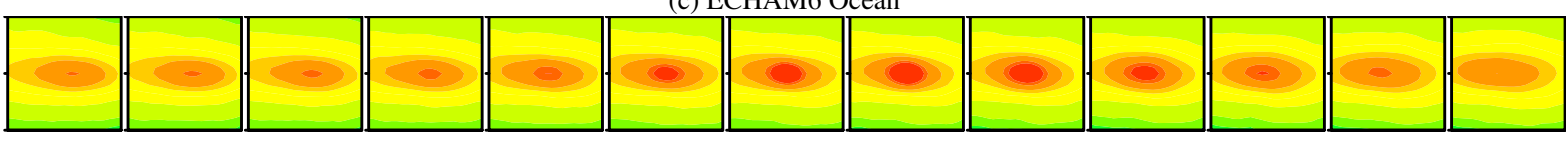

(d) CAM5 Ocean

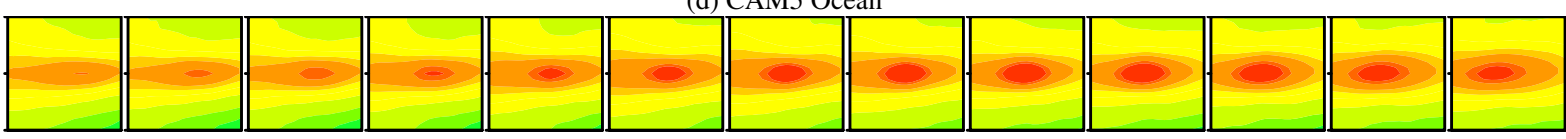

(e) 2C-ICE Land

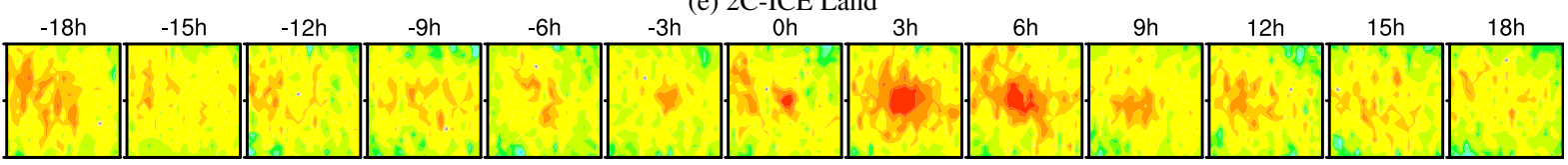

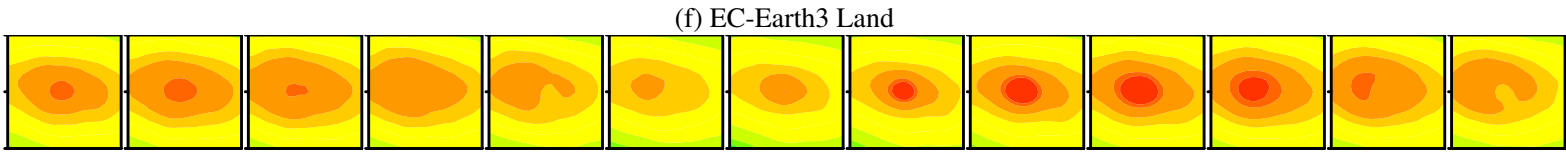

(g) ECHAM6 Land

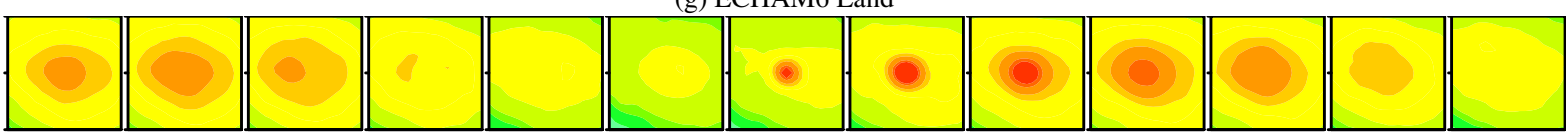

(h) CAM5 Land
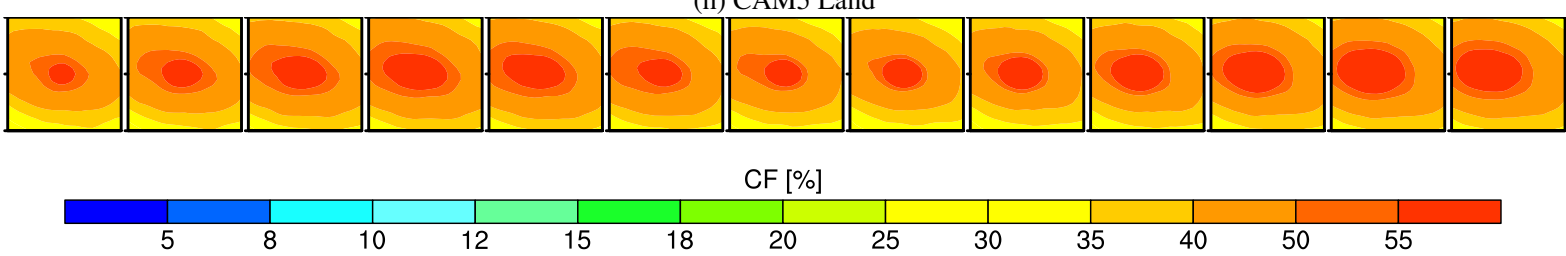

Figure 6. Composite of cloud fraction (CF) at $200 \mathrm{hPa}$ for ocean-based (a-d) and land-based (e-h) systems for 2C-ICE followed by the models. The spatio-temporal coverage of $\pm 18 \mathrm{~h}$ at every $3 \mathrm{~h}$ interval and $\pm 10^{\circ}$ longitude and latitude is taken from the centre point and graduated every $\pm 1^{\circ}$.

for ocean-based systems. Negative $\mathrm{CF}$ anomalies can be seen around $-33,-9,15$, and $39 \mathrm{~h}$. A secondary, and much weaker, $\mathrm{CF}$ maximum is seen about $24 \mathrm{~h}$ after peak convection, while at $-24 \mathrm{~h}$ the cloud fraction anomaly is slightly negative.

The models' land-based DC systems show much greater disparity with 2C-ICE than the ocean-based systems. Most notably, a stronger diurnal cycle of $\mathrm{CF}$ anomalies is present in the models than in 2C-ICE at the same location. Within $\pm 48 \mathrm{~h}$, all models show four distinct anomalies of roughly similar magnitudes, whereas 2C-ICE only indicates one clear case, centred at hour 0 . The 2C-ICE positive land-based CF anomalies begin at $0 \mathrm{~h}$, but the models seem to start later relative to the time of maximum RR. There is also a distinct tilt in the model anomalies, which appear first at high levels and then propagate downward. This is less obvious in 2C-ICE. While 2C-ICE does indicate some activity around -21 and $27 \mathrm{~h}$, these $\mathrm{CF}$ anomalies are significantly smaller 

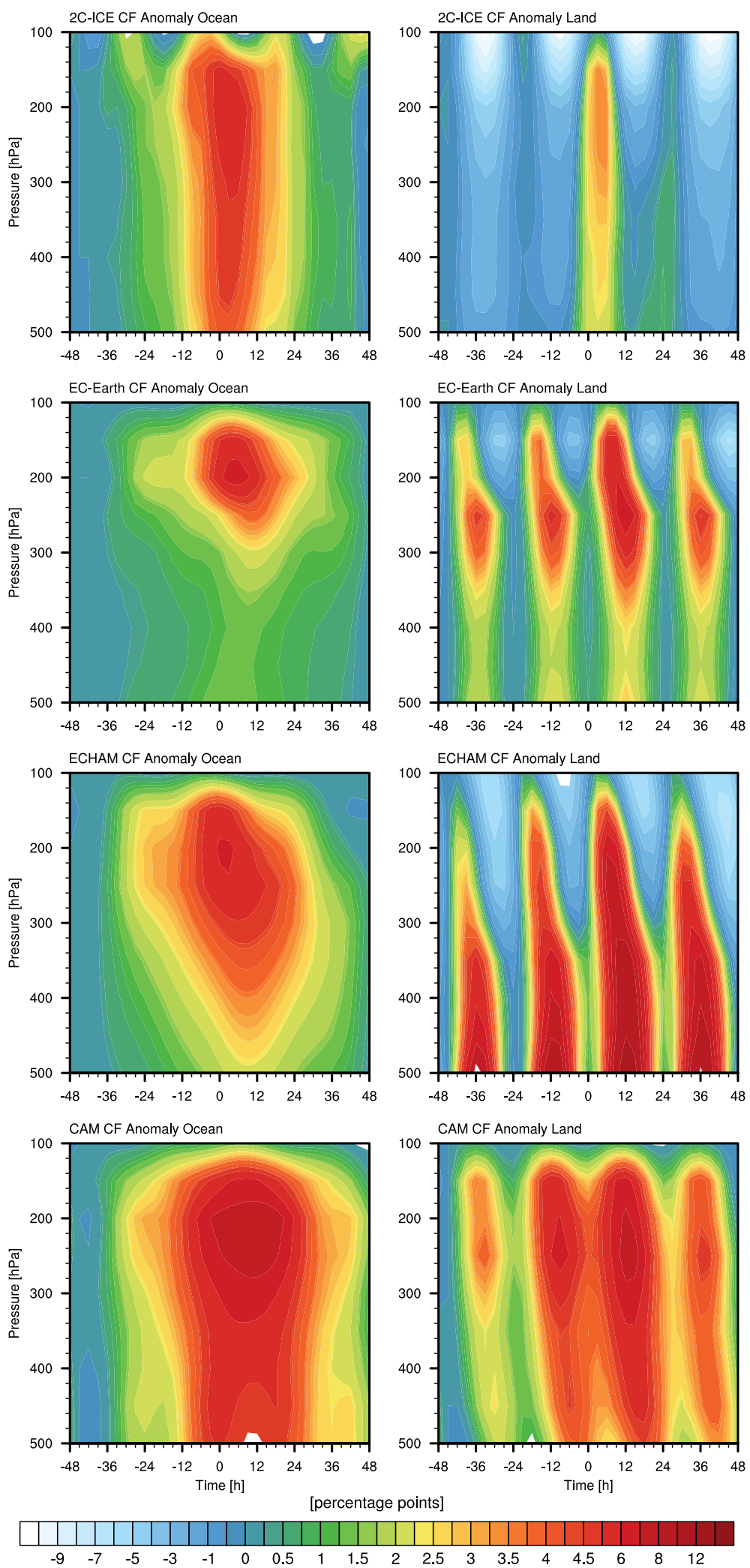

Figure 7. Cloud fraction (CF) anomaly for ocean-based (left column) and land-based (right column) systems. The data are averaged over the area $\pm 3^{\circ}$ latitude, $\pm 10^{\circ}$ longitude, and temporally $\pm 48 \mathrm{~h}$ from the centre point of peak rain rate. The results are smoothed using a $12 \mathrm{~h}$ running mean. The background state is the spatio-temporal mean of the earliest four time bins. 
than in the models by up to 10 percentage points. This suggests that the models might be triggering deep convection too often in the geospatial grid used to create the composite. Similar to 2C-ICE, EC Earth3's cloud fraction anomalies are greatest around $250 \mathrm{hPa}$ and decrease with increasing pressure. CAM5 and ECHAM6 do not show this decrease in their anomalies at these higher pressure levels.

\subsubsection{Cloud ice water content}

Individual GCMs parameterise IWC differently, and this is reflected in the results. See Johnston et al. (2012) for an indepth look of the treatment of ice in EC-Earth3 and Waliser et al. (2009) for a general overview of this treatment in a number of models from the Coupled Model Intercomparison Project phase 3. In particular, it is of note that the IWC available from the models only includes stratiform cloud ice and lacks the snow hydrometeors from the stratiform and convective parameterisations that are present in the observed estimates of IWC. However, most probably, this does not greatly affect the general spatio-temporal distribution of IWC in these upper levels. To demonstrate this, CAM5's largescale snow was added to the suspended ice (not shown). Although at lower altitudes this added significant IWC, at $200 \mathrm{hPa}$ the increase in IWC is small and the spatio-temporal patterns are the same. While it is possible to perform some separation of precipitating and non-precipitating ice, as suggested by Chen et al. (2011), the models do not all partition these categories of ice along clear and generally well-defined particle sizes. This fact makes it difficult to partition 2C-ICE to match a set of models. Nevertheless, the models' standard IWC is enough for a first step comparison where the focus is on the general spatio-temporal patterns.

The mean IWCs at $200 \mathrm{hPa}$ for $2 \mathrm{C}$-ICE and the models are shown in Fig. 8. In 2C-ICE over the ocean, elevated values of IWC cover a broad portion of the domain in each time bin with somewhat zonally elongated regions of elevated IWC at the domain centre. Away from the domain centre, IWC values up to $\sim 20 \mathrm{mg} \mathrm{m}^{-3}$ are present throughout the composite.

Over ocean, the models show the typical zonally elongated spatial patterns of IWC similar to 2C-ICE. Among the models, EC-Earth3 reports the highest amount of ice at this level, with values locally ranging from $\sim 2$ to $15 \mathrm{mg} \mathrm{m}^{-3}$. CAM5 and ECHAM6 have values typically $\lesssim 5 \mathrm{mg} \mathrm{m}^{-3}$. In the models, elevated values of IWC at the domain centre appear first around $0 \mathrm{~h}$ and last until approximately $9 \mathrm{~h}$.

Over land, the 2C-ICE IWC in each time bin also shows broad spatial coverage of values $\gtrsim 30 \mathrm{mg} \mathrm{m}^{-3}$. However, for these systems, the domain centre is a focal point rather than a part of a zonally elongated region of elevated values, much like the RR patterns. Between hours -6 and 6, enhanced IWC is present at the domain centre, with values similar to those seen in the ocean-based composite. The spatiotemporal mean IWC over land regions is $\approx 19 \mathrm{mg} \mathrm{m}^{-3}$, which is nearly twice as large as that over ocean regions $\left(\approx 11 \mathrm{mg} \mathrm{m}^{-3}\right)$.

For land-based systems, EC-Earth3 is again the model with the most ice. The spatio-temporal mean IWC for landbased systems is also greater than that for the ocean-based systems, as in 2C-ICE. The IWC displays a radially symmetric spatial pattern which is in good agreement with $2 \mathrm{C}$ ICE. In all models, there is evidence of elevated IWC at the domain centre at $-18 \mathrm{~h}$, which then decreases as time approaches $0 \mathrm{~h}$, before again rising sharply. This points to a strong diurnal cycle in the IWC, consistent with the CF and other upper-tropospheric quantities.

\subsubsection{IWC time-altitude anomaly}

In Fig. 9 the temporal effect of DC systems on the vertical distribution of IWC is examined. Similar to the CF, both the simulated and 2C-ICE time-altitude IWC anomalies are smoothed. Large inter-model differences and model to satellite retrieval differences in the diurnal cycle, the placement of ice both vertically and in time, and the magnitude of the IWC anomalies are evident in Fig. 9.

2C-ICE over oceanic areas shows a strong response to the DC systems that extends throughout most of the upper troposphere to about $150 \mathrm{hPa}$. Upper-tropospheric IWC anomalies emerge some time around $-12 \mathrm{~h}$, with the maximum IWC values occurring at $3 \mathrm{~h}$ and between 500 and $250 \mathrm{hPa}$. Also, between these pressure levels, ocean-based systems show the greatest increase in IWC, with a duration of about $\sim 30 \mathrm{~h}$. The IWC anomalies increase with increasing pressure from around $\sim 5 \mathrm{mg} \mathrm{m}^{-3}$ at $200 \mathrm{hPa}$ to $\sim 20 \mathrm{mg} \mathrm{m}^{-3}$ at $450 \mathrm{hPa}$. There is an indication of a diurnal cycle in these anomalies, which is most distinct at pressure levels $<300 \mathrm{hPa}$. Finally, there is a notable tilt, where IWC anomalies belonging to the same DC system appear earlier in time at higher rather than at lower heights. This tilt is equally pronounced over land and ocean areas. This feature could partly be the result of the rate of ice particle formation, and the sedimentation of stratiform cloud ice. However, further investigation into these aspects is beyond the scope of this study.

Over ocean areas the spatio-temporal structure of simulated IWC anomalies varies greatly from 2C-ICE. The spatio-temporal distribution of the EC-Earth3 anomaly is closest to 2C-ICE, with roughly three distinct plumes that penetrate the upper troposphere to pressure levels close to $100 \mathrm{hPa}$. ECHAM6's IWC anomaly is limited to pressure levels $>200 \mathrm{hPa}$, and its maximum of $\sim 3 \mathrm{mg} \mathrm{m}^{-3}$ occurs around $350 \mathrm{hPa}$. Near $500 \mathrm{hPa}$, ECHAM6's anomaly approaches zero, which is also due to the exclusion of snow. The vertical distribution pattern of CAM5's anomalies indicates that the IWC response to DC systems occurs mainly at pressure levels between 350 and $150 \mathrm{hPa}$. The magnitude of the IWC response in CAM5 is of the order of $\sim 1 \mathrm{mg} \mathrm{m}^{-3}$, which is the lowest of all the models. At pressure levels $>350 \mathrm{hPa}$, CAM5's IWC anomalies reduce to zero, which 


\begin{tabular}{|c|c|c|c|c|c|c|c|c|c|c|c|c|}
\hline \multicolumn{13}{|c|}{ (a) 2C-ICE Ocean } \\
\hline$-18 \mathrm{~h}$ & $-15 h$ & $-12 \mathrm{~h}$ & $-9 \mathrm{~h}$ & $-6 \mathrm{~h}$ & $-3 \mathrm{~h}$ & $\mathrm{Oh}$ & $3 \mathrm{~h}$ & $6 \mathrm{~h}$ & $9 \mathrm{~h}$ & $12 \mathrm{~h}$ & $15 \mathrm{~h}$ & $18 \mathrm{~h}$ \\
\hline & & & & & 2 & 4 & 7 & & & 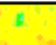 & & 7 \\
\hline & & 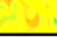 & 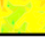 & 4 & & & 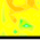 & 4 & c & 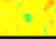 & 8 & \\
\hline
\end{tabular}

(b) EC-Earth3 Ocean

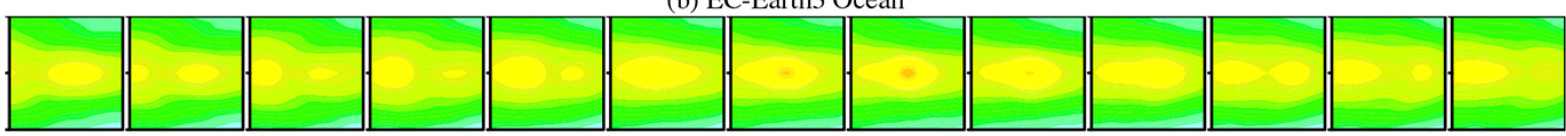

(c) ECHAM6 Ocean

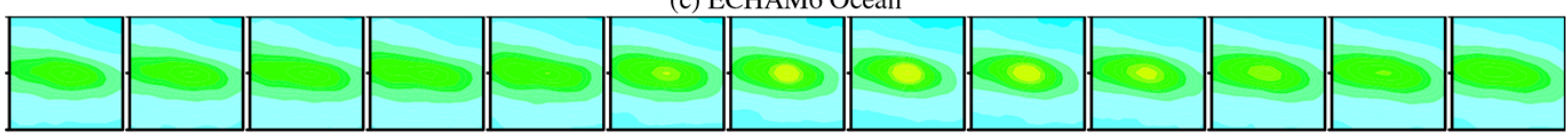

(d) CAM5 Ocean

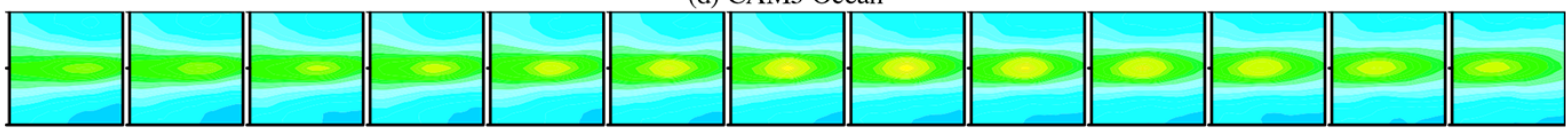

(e) 2C-ICE Land

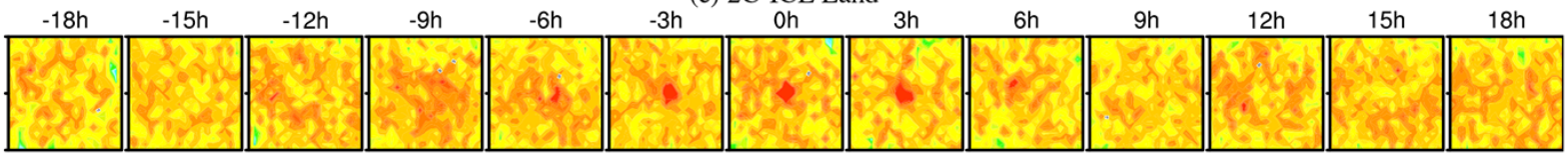

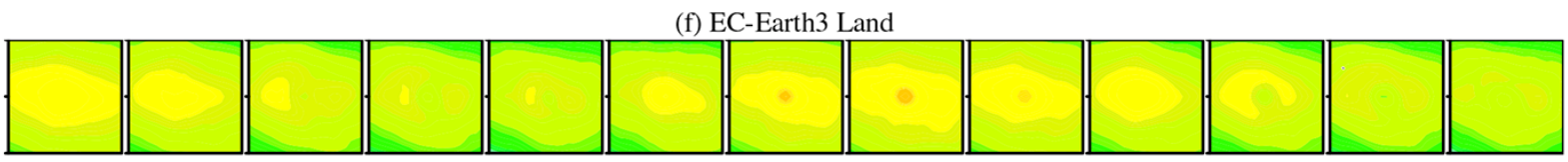

(g) ECHAM6 Land

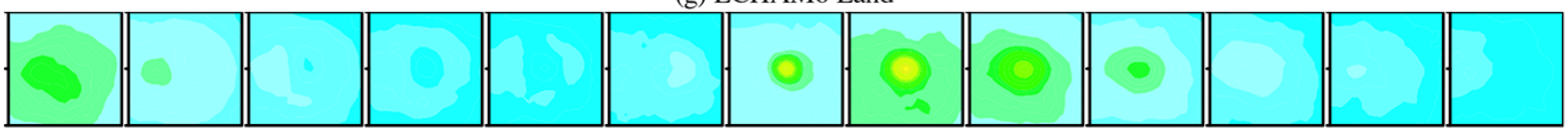

(h) CAM5 Land

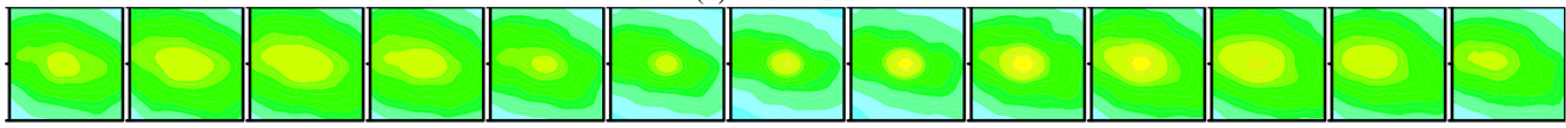

IWC $\left[\mathrm{mg} \mathrm{m}^{-3}\right]$

$\begin{array}{lllllllllllllllllllllllll}0.2 & 0.4 & 0.6 & 0.8 & 1 & 1.2 & 1.4 & 1.6 & 1.8 & 2 & 2.4 & 2.8 & 3.5 & 4.2 & 4.6 & 5 & 6 & 12 & 14 & 20 & 30 & 40 & 50 & 60 & 70\end{array}$

Figure 8. Composite of ice water content (IWC) at $200 \mathrm{hPa}$ for ocean-based (a-d) and land-based (e-h) systems for 2C-ICE followed by the models. The spatio-temporal coverage of $\pm 18 \mathrm{~h}$ at every $3 \mathrm{~h}$ interval and $\pm 10^{\circ}$ longitude and latitude is taken from the centre point and graduated every $\pm 1^{\circ}$.

is largely due to the exclusion of the snow components of the IWC.

The largest IWC anomalies for the models are $\sim 2 \mathrm{mg} \mathrm{m}^{-3}$ for EC-Earth3, $\sim 3 \mathrm{mg} \mathrm{m}^{-3}$ for ECHAM6, and $\sim 1 \mathrm{mg} \mathrm{m}^{-3}$ for CAM5, which are all much smaller than the 2C-ICE anomalies. Furthermore, although there is a hint of a tilt in the IWC profiles at pressures less than $300 \mathrm{hPa}$ for EC-Earth3 and CAM5 (i.e. the signal first appearing at the upper levels and then proceeding downwards), none of the models' ocean-based systems appear to exhibit the tilt in the anomaly for pressures greater than $300 \mathrm{hPa}$ seen in 2C-ICE.

The simulated ocean-based anomalies have more diffuse diurnal cycles relative to those over land. CAM5 has virtually no additional anomalies apart from peak convection. ECHAM6 shows additional anomalies at approximately \pm 36 and $\pm 12 \mathrm{~h}$, which is an indication of its diurnal cycle. The anomalies of EC-Earth 3 occur at $\pm 24 \mathrm{~h}$ in addition to peak convection. Unlike EC-Earth3 and 2C-ICE, the IWC 

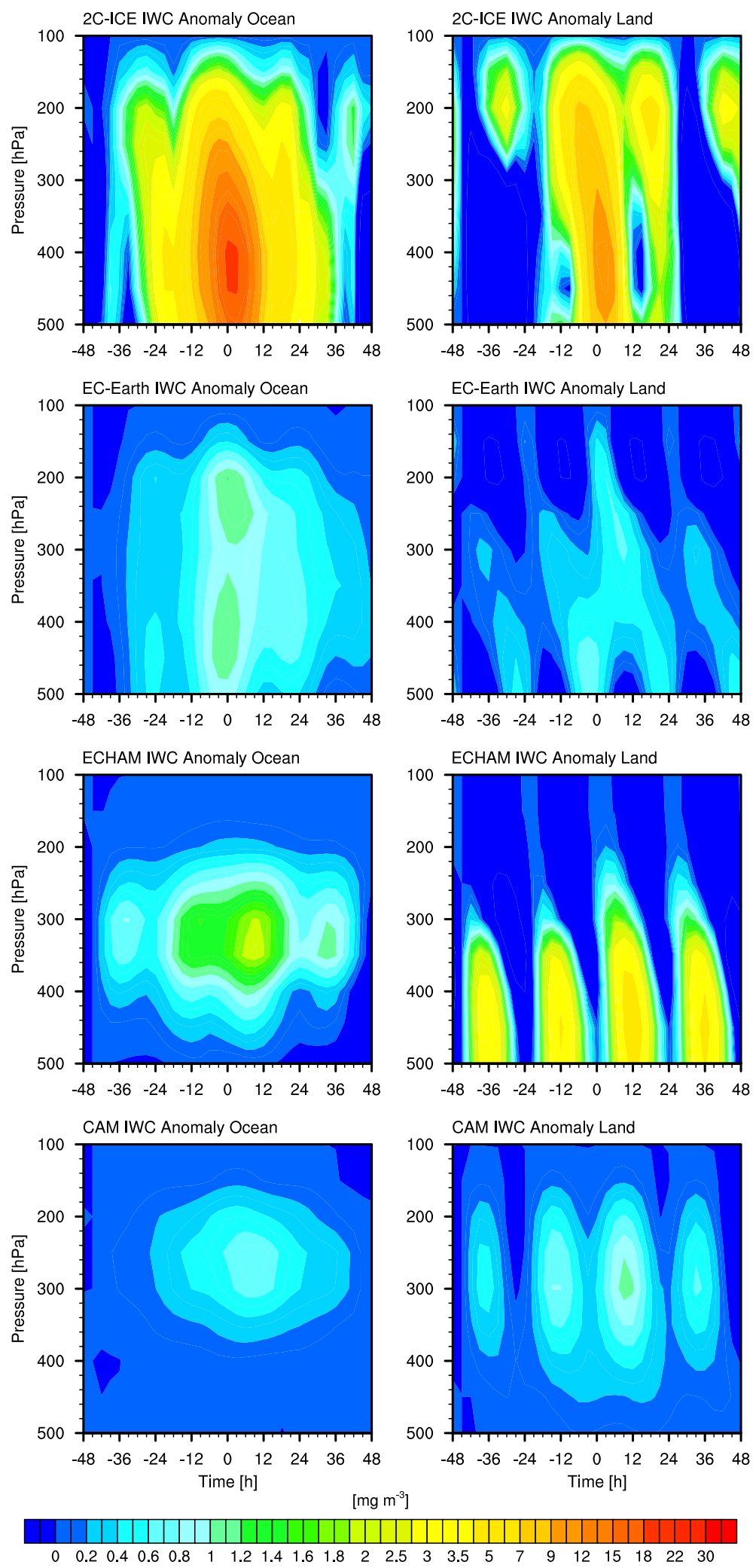

Figure 9. Ice water content (IWC) anomaly for ocean-based (left column) and land-based (right column) systems. The data are plotted for the area $\pm 3^{\circ}$ latitude, $\pm 10^{\circ}$ longitude, and $\pm 48 \mathrm{~h}$ from the centre point of peak rain rate (RR). The results are smoothed using a $12 \mathrm{~h}$ running mean. The background state is the spatio-temporal mean of the earliest four time bins. 
anomalies corresponding to peak convection of CAM5 and ECHAM6 are not centred at $0 \mathrm{~h}$, which could indicate that detrained ice remains as anvil cirrus for a longer time.

Land-based DC systems derived from the 2C-ICE data set penetrate the upper troposphere to slightly higher heights than their ocean-based counterparts. The duration of the anomaly is $\sim 20 \mathrm{~h}$. The diurnal cycle is quite dissimilar between land and ocean DC systems. Over the ocean areas there are two notable peaks in the IWC anomaly at $\approx \pm 24 \mathrm{~h}$. Out of these, the anomaly after peak convection is stronger than the one prior to it; however, both anomalies are significantly weaker than the main system anomaly centred at $0 \mathrm{~h}$.

Over land, the agreement between the models is better than over ocean. All of the models show a strong diurnal cycle of convection in contrast to $2 \mathrm{C}$-ICE. The land-based anomalies show a shorter and more distinct duration than the oceanbased systems. EC-Earth3 and CAM5 show similar values of $\sim 2 \mathrm{mg} \mathrm{m}^{-3}$, but ECHAM6 anomalies show a larger increase at pressures greater than $300 \mathrm{hPa}$ to values of around $\sim 9 \mathrm{mg} \mathrm{m}^{-3}$. For these systems, the models show some tilt in the anomalies. Above $300 \mathrm{hPa}$, the timing of the peak diurnal IWC anomaly, associated with the stratiform anvil cloud, is similar for all models (as also shown for $200 \mathrm{hPa}$ in Fig. 8), with a slight delay behind the observed anomaly of 3 to $6 \mathrm{~h}$. However, below $300 \mathrm{hPa}$ the timing of the IWC anomalies is very different. The main anomalies of CAM5 and ECHAM6 are about $12 \mathrm{~h}$ out of phase with 2C-ICE. In contrast, ECEarth3's anomalies are centred on peak convective RR and $\pm 24 \mathrm{~h}$, which is close to 2C-ICE. However, the tilt in the model anomalies reaches back farther in time than in $2 \mathrm{C}$ ICE. The reason for these differences requires further investigation but may be related to the different convective detrainment formulations in the models. All models have slightly larger IWC following the main event compared to $\pm 24 \mathrm{~h}$, but the difference is not as marked as in 2C-ICE. Including stratiform and convective precipitating snow components from the models would increase the IWC significantly at these lower levels, may change the timing of peak anomaly, and would be a fairer comparison with the 2C-ICE IWC, but unfortunately these components are not available for all models for this study.

\subsubsection{Outgoing longwave radiation}

The CERES OLR shown in Fig. 10 for both ocean and land DC system types is in fair agreement with the spatial patterns seen in the AMSU UTH. The ocean-based systems show a decrease in OLR at the domain centre of the composite at approximately $-9 \mathrm{~h}$. The minimum in OLR is not located at $0 \mathrm{~h}$ but rather around $3 \mathrm{~h}$, which suggests a maximum coverage by anvil clouds around that time. The spatial coverage of the OLR minimum at $3 \mathrm{~h}$ is about $300 \mathrm{~km} \times 400 \mathrm{~km}$, which is in agreement with the dimensions of convective clusters (Houze, 1989, Fig. 2). Relaxation of the OLR back to the mean state occurs between 15 and $18 \mathrm{~h}$.
For ocean-based systems, all models show an emergence and dissipation of an area of minimum OLR at the domain centre. For ECHAM6 and EC-Earth3, this first appears roughly between time bins -6 and $-3 \mathrm{~h}$ and lasts until around $9 \mathrm{~h}$. However, CAM5's minimum appears at $-15 \mathrm{~h}$ and lasts beyond $18 \mathrm{~h}$, which is similar to CERES. The models show higher OLR across the domain than CERES. This could be caused by the north-south extent of the model DC systems' CF being too narrow, in particular at the northern boundary of the domain. However, since the vertical extent of the simulated clouds is comparable to CERES (Fig. 7) and there is a distinct overproduction of $\mathrm{CF}$ at $200 \mathrm{hPa}$ (Fig. 6), the most probable explanation for the positive OLR bias is that the IWC is underestimated (Fig. 8), which makes the model clouds too transparent. At the domain centre of the DC systems, CAM5's spatial pattern is closest to CERES, as the other models overestimate OLR at the domain centre.

The CERES land-based systems, similar to the composite results of the other variables, are markedly different from those over oceans. There is a distinct increase in the OLR from time bins -18 to $-6 \mathrm{~h}$, which suggests a relaxation from earlier convection. Indications of the DC systems can be seen sometime between -6 and $-3 \mathrm{~h}$, which lasts until about $15 \mathrm{~h}$. For both types of DC systems, the OLR can locally fall below $180 \mathrm{~W} \mathrm{~m}^{-2}$; however, the spatial coverage of the OLR minimum is larger than for ocean-based systems, roughly $400 \mathrm{~km} \times 400 \mathrm{~km}$.

Over land, all the models agree quite well with CERES in showing a decrease in OLR starting between -3 and $0 \mathrm{~h}$, but the spatial extent of the decrease in OLR is consistently smaller in the models. Throughout the temporal extent of the composite there is a notable absence of higher OLR at the edge of the domain. This suggests that the clouds generated by land-based systems have a far greater spatial coverage than ocean-based systems, which agrees well with CERES. EC-Earth3 and ECHAM both show similar diurnal effects in time bins -18 to around $-3 \mathrm{~h}$, where the OLR is increasing, quite likely in response to dissipating clouds from earlier convection. The timing of minimum OLR is distinct in ECHAM6 and EC-Earth3, which place it around $3 \mathrm{~h}$. In CAM5 the minimum is not very clear and occurs sometime between 3 and $9 \mathrm{~h}$. The overall effect of the DC systems on OLR lasts longer in CAM5 than in the other two models, consistent with the slower decay of IWC (Fig. 8). In both ECHAM6 and EC-Earth3, cloud dissipation after peak convection takes about $18 \mathrm{~h}$.

Both over ocean and land, the spatial coverage of the area showing a decrease in OLR at the centre of the models' domain is consistently smaller than in CERES.

\subsubsection{Zonal propagation of convection}

Figure 11 shows Hovmöller diagrams of RR as a function of longitude and time for a randomly chosen 7-day period in the TMPA data set and models, and provides an indication of 


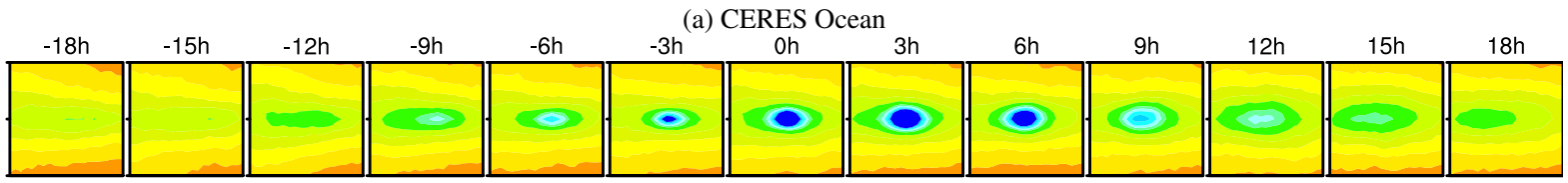

(b) EC-Earth3 Ocean

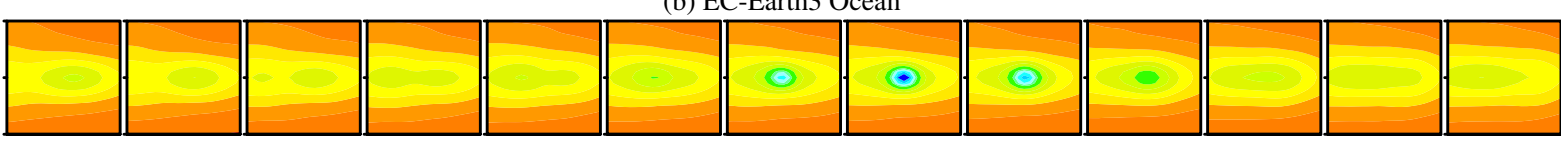

(c) ECHAM6 Ocean

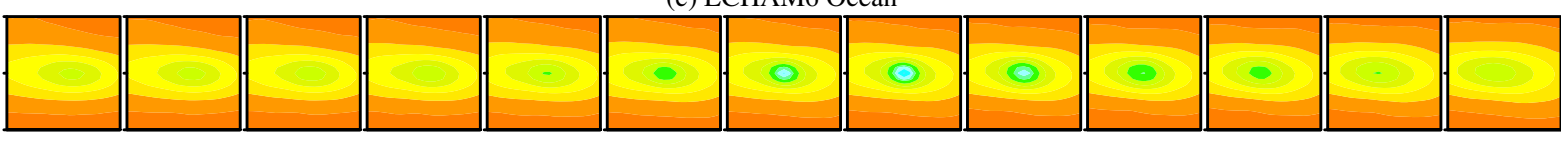

(d) CAM5 Ocean

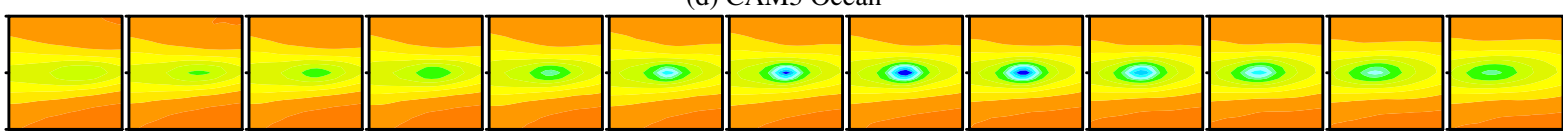

(e) CERES Land

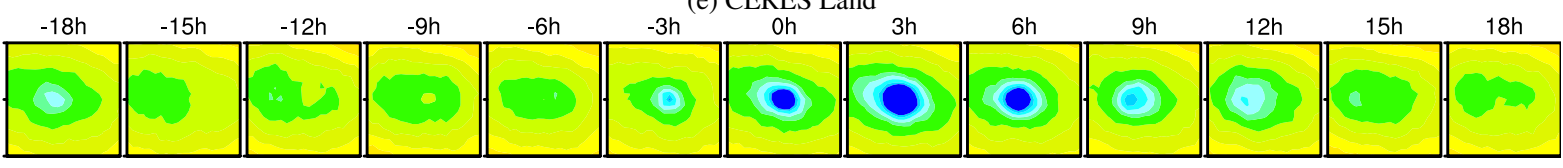

(f) EC-Earth3 Land

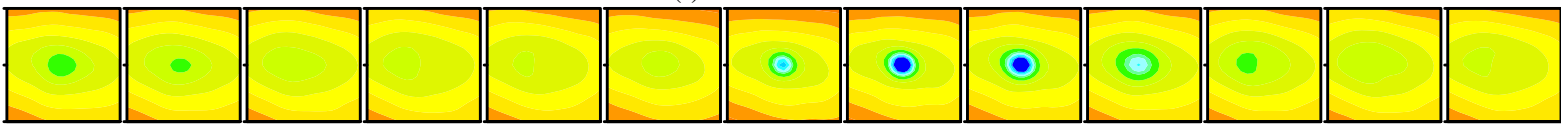

(g) ECHAM6 Land

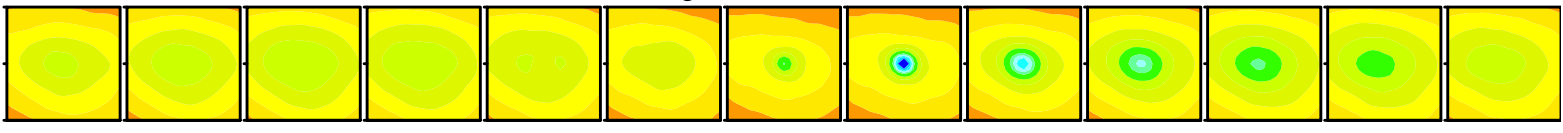

(h) CAM5 Land
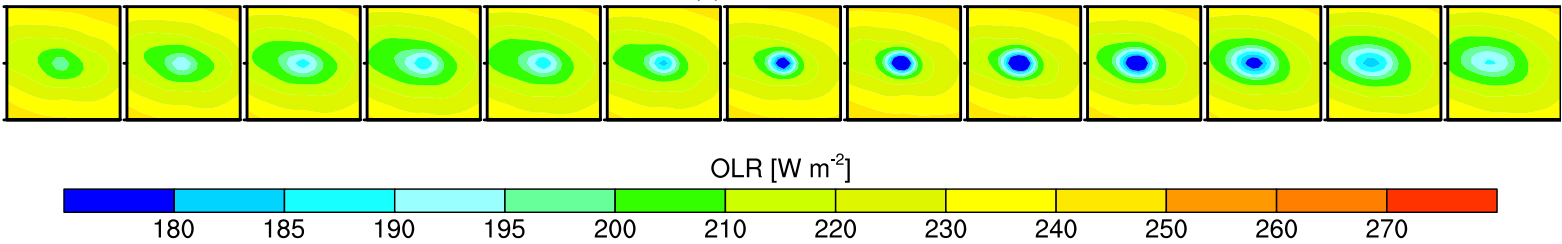

Figure 10. Composite of outgoing longwave radiation (OLR) for ocean-based (a-d) and land-based (e-h) systems for the Cloud and Earth Radiant Energy System (CERES) followed by the models. The spatio-temporal coverage of $\pm 18 \mathrm{~h}$ at every $3 \mathrm{~h}$ interval and $\pm 10^{\circ}$ longitude and latitude is taken from the centre point and graduated every $\pm 1^{\circ}$.

the motion of convective activity. Following Blackburn et al. (2013, Fig. 16), only the activity within $\pm 5^{\circ}$ latitude is examined. Similar to Johnston et al. (2013, Fig. 7), Hovmöller diagrams averaged over all DC systems included in the composites, separately for ocean-based and land-based convection, are shown in Fig. 12.

TMPA from the 7 days examined shows convection moving zonally in both directions. The predominant motion around 60 and $120^{\circ} \mathrm{E}$ appears to be eastward, but around
180 and $60^{\circ} \mathrm{W}$ the motion is opposite. Furthermore, at some meridians, both eastward and westward motions occur but at different times. When averaged (Fig. 12), the TMPA DC systems tend to show a westward motion, regardless of surface type. This could be interpreted as fast-moving systems moving west embedded within slower moving envelopes of convection moving east.

The models also exhibit zonally propagating convection. As in TMPA, both westward- and eastward-propagating 

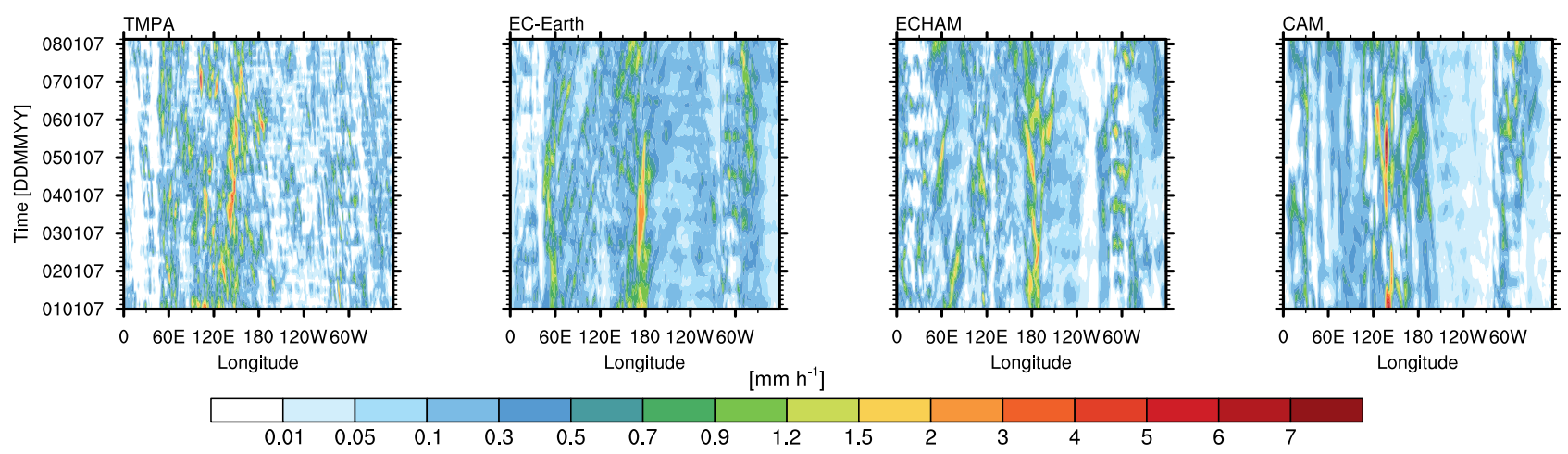

Figure 11. Time-longitude illustration of all rain rates across the tropics within $\pm 5^{\circ}$ latitude.

equatorial waves are present in the models. These results are in agreement with Blackburn et al. (2013), who examined the motion of equatorial precipitation for a 30-day period for 16 different models and found similar differences between a range of models. Over the ocean, EC-Earth3 exhibits relatively fast eastward-moving DC systems embedded within slower westward-propagating convective envelopes. The remaining models show no clear zonal motion. Over land, the models show no zonal motion.

Another interesting feature of Fig. 12 is the occurrence of convection at $\pm 24 \mathrm{~h}$. Over ocean, TMPA and simulated results all tend to place successive convection westward in time. The simulated land-based DC systems in Fig. 12, on the other hand, show a diurnal cycle of convection of nearly similar intensity at the same longitude, which is not seen in TMPA.

\section{Summary and conclusion}

This study highlights the evolution of tropical deep convective systems over ocean and land in three prominent GCMs (EC-Earth3, ECHAM6, and CAM5) and compares them with a range of satellite-based results. A composite technique is employed to compile model and satellite data around thousands of deep convective systems that are identified using local rain rate maxima. The ability of this technique to capture the evolution of deep convection in a GCM is demonstrated in Johnston et al. (2013). The effects of deep convection are investigated and compared for several upper-tropospheric variables related to moist processes (relative humidity, cloud fraction, and ice water content) and outgoing longwave radiation.

The models capture the evolution of deep convection in a largely similar manner to what is seen in the satellite data, but there are significant aspects of simulated DC systems that diverge from the satellite results. When considering the total RR across the tropics, the models show an overproduction of light precipitation $\left(\lesssim 3 \mathrm{~mm} \mathrm{~h}^{-1}\right)$ and an underestimation of the occurrence of higher RR intensities compared to TMPA.
This positive bias is due partly to a negative bias in TMPA RRs based on AMSU data over ocean areas (Huffman et al., 2007). The diurnal distribution of the DC system RRs in the models is similar to TMPA for ocean-based systems; however, land-based systems peak several hours too early. Both of these are common problems in GCMs that have been previously identified but are important to show as this study relies on the RR as defining the deep convective events. The models' UTHs agree qualitatively with the AMSU UTHs; however, all the models tend to have higher relative humidities, with CAM5 having the highest UTH. Nevertheless, the models show a similar effect of DC systems on the cloud fractions at $200 \mathrm{hPa}$, similar to the $\mathrm{CF}$ derived from the $2 \mathrm{C}$ ICE data set. CAM5, however, consistently reports higher CF across the domain for both land- and ocean-based systems.

The 2C-ICE cloud fraction includes the presence of all hydrometeors, whereas the representation of cloud fraction in the models varies. For EC-Earth3, CF is a prognostic variable with sources from convective detrainment and nucleation of cloud ice. The hydrometeor fraction associated with the precipitating snow category is not included, and hence the $\mathrm{CF}$ is significantly lower than $2 \mathrm{C}$-ICE for pressure levels $>300 \mathrm{hPa}$. In contrast, $\mathrm{CF}$ is a diagnostic variable in ECHAM6 and CAM5, and, although similarly there is no fraction associated with precipitating snow, the CF is significantly higher at these lower altitudes for these two models. Over ocean areas, the modelled CF anomalies reach their maximum at levels close to $200 \mathrm{hPa}$. While this is also true for EC-Earth3 over land, the CAM5 and ECHAM6 anomaly maxima are spread throughout the upper troposphere almost simultaneously. While the models' performance for oceanbased systems seems to capture the evolution of DC systems fairly well, the land-based systems show significant discrepancies. In particular, the models have a significantly stronger diurnal cycle at the same geospatial position. A possible explanation could lie in the CAPE (convective available potential energy)-based closure assumptions in each model. However, further investigation is needed to confirm this hypothesis. 

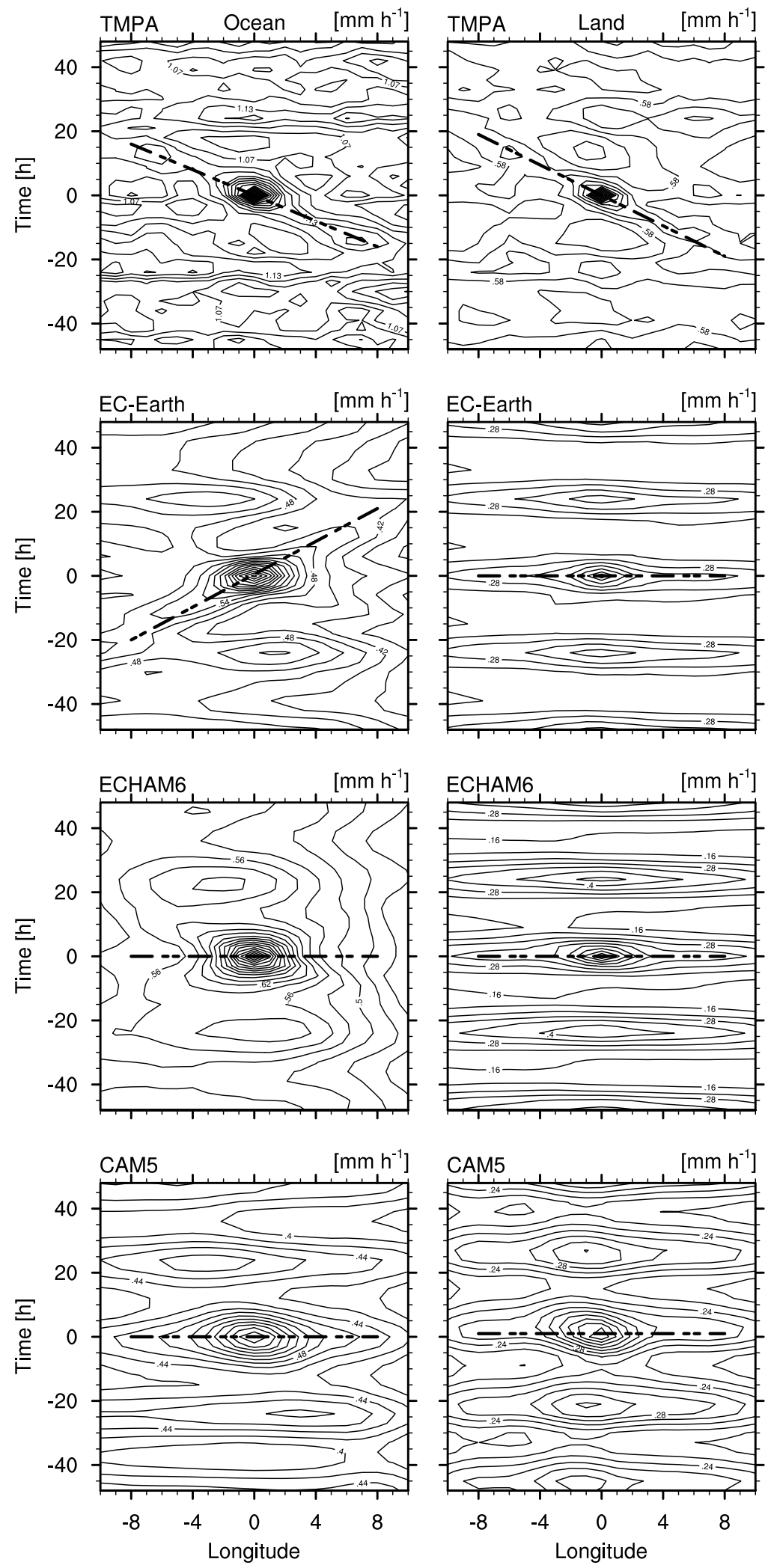

Figure 12. Hovmöller diagrams of rain rates centred on composite DC systems, for Tropical Rainfall Measuring Mission Multi-satellite Precipitation Analysis (TMPA), ECHAM6, CAM5, and EC-Earth3 for (left) ocean-based systems and (right) land-based systems. The lines drawn on the figures are visual aids indicating the various directions of zonal motion: eastward, westward, or stationary. 
The 2C-ICE spatio-temporal mean IWCs at $200 \mathrm{hPa}$ are $\sim 11 \mathrm{mg} \mathrm{m}^{-3}$ over ocean and $\sim 19 \mathrm{mg} \mathrm{m}^{-3}$ over land. DC systems can raise these IWCs in proximity to the convective domain centre to $\sim 70 \mathrm{mg} \mathrm{m}^{-3}$, which decreases rapidly after peak convection. Although the spatio-temporal mean IWCs differ, the magnitudes of the anomalies are about the same for land- and ocean-based systems. However, there are significant uncertainties in 2C-ICE IWC (Austin et al., 2009). Information about the different phases in upper-tropospheric water is difficult to retrieve from satellites, and, therefore, the 2C-ICE product is strongly sensitive to assumptions regarding the separation of ice and liquid water and particle size distribution. This points to the need for pseudo-satellite simulators in the future for alternative comparisons of model and satellite data (Bodas-Salcedo et al., 2011).

The models are able to capture the overall statistical spatial patterns of IWC over both land and ocean at $200 \mathrm{hPa}$. EC-Earth3 reports the greatest amount of ice at this level, with values locally reaching up to $\sim 15 \mathrm{mg} \mathrm{m}^{-3}$ for both system types. CAM5 and ECHAM6 have considerably lower values, typically $<3 \mathrm{mg} \mathrm{m}^{-3}$. Similar IWC magnitudes for earlier versions of these models were found by Eriksson et al. (2010) using retrievals from CloudSat and Odin. The maximum IWC at $200 \mathrm{hPa}$, for each model, lasts about $9 \mathrm{~h}$ and is consistently lower in magnitude than seen in 2C-ICE, even when adding in the stratiform snow component to the IWC in CAM5.

The 2C-ICE time-altitude IWC anomalies over both surface types reach $100 \mathrm{hPa}$. Anomalies for maritime systems emerge roughly about $10 \mathrm{~h}$ prior to maximum convection, with peak values between $\approx 500$ and $250 \mathrm{hPa}$. Ocean-based systems show a greater increase in IWC anomaly and with a longer duration than for land-based ones, $\sim 30$ versus $\sim 20 \mathrm{~h}$ respectively. Between 200 and $100 \mathrm{hPa}$, the anomaly can reach $\sim 5 \mathrm{mg} \mathrm{m}^{-3}$, but at lower heights this anomaly can be up to four times larger.

The modelled time-altitude IWC anomalies over land have a strong diurnal cycle. Over ocean, this diurnal cycle is less distinct. Such a strong diurnal signal in the models suggests that they have more of a tendency for convection to trigger at the same location from day to day than in $2 \mathrm{C}$ ICE, or possibly an inability to capture the variability in convective strength from day to day. The timing of the IWC at pressures $<300 \mathrm{hPa}$ is similar, but the behaviour for pressures $>300 \mathrm{hPa}$ is very different in the different models. ECEarth3's IWC anomalies are centred around peak convection, which is close to 2C-ICE peak at these levels. CAM5 shows a hint of this signal around $450 \mathrm{hPa}$, but the main IWC anomalies of CAM5 and ECHAM6 are both centred $12 \mathrm{~h}$ out of phase with $2 \mathrm{C}$-ICE. The latter feature may be related to the fact that the majority of IWC reported by $2 \mathrm{C}$-ICE is convective, precipitating snow, which reaches its maximum at peak RR but was not stored by the models. However, the comparison does highlight significant differences in the representation of cloud ice associated with DC systems and could be the subject of further investigation beyond the scope of this study.

The spatial coverage of observed DC systems' clouds over ocean is typically $300 \mathrm{~km} \times 400 \mathrm{~km}$, which is in agreement with Houze (1989, Fig. 2). The land-based systems tend to cover an even larger area. For both types of DC system, the OLR can locally fall below $180 \mathrm{~W} \mathrm{~m}^{-2}$. The models agree with CERES with regards to the minimum OLR reached within the DC systems. However, for ocean-based systems, the modelled OLR is consistently larger than CERES outside the domain centre. This is due to the smaller spatial extent of the models' DC systems. Over land, all the models agree quite well with CERES in showing a similar timing in the OLR minimum, slightly after the peak RRs, but the spatial extent of OLR decrease is consistently smaller in the models.

There is some propagation of deep convective systems apparent in the models, but the relative magnitudes of eastwardand westward-propagating motion do not agree with TMPA. For example, any such motion is absent from land-based systems, while only EC-Earth3 and ECHAM6 show some propagation for ocean-based systems, with EC-Earth3's systems apparent movement mostly opposite to that seen in TMPA.

This study has evaluated the representation of the effects of tropical deep convective systems on the upper-troposphere for three global climate models using a novel compositing technique to focus on the temporal evolution compared to satellite-derived data. The evaluation highlights a good degree of agreement of the spatio-temporal patterns of UTH, cloud fraction, ice water content and OLR in the upper troposphere around $200 \mathrm{hPa}$ between all the models and the satellite data. However, there are significant differences in the magnitude and exact timing of the anomalies relative to the time of peak surface rain rate. Similar OLR in the models is achieved with different cloud fractions and ice water contents and highlights the potential for compensating errors in the models leading to reasonable radiative fluxes. A key motivation for this study is to identify systematic errors in multiple cloud-related quantities to inform model development, so that the correct radiative fluxes can be achieved in models for the right reasons. The study also highlights the difficulties of comparing cloud fraction and ice water contents due to the different representation and definitions between simulated and satellite-retrieved variables. Additional model output including all components of the IWC should be standardly available from global climate model simulations in the future in order to perform a fair comparison with satellite data, either through the use of model forward operators or geophysical retrievals. The detailed representation of deep convection through parameterisation in a GCM remains a challenge, particularly for the temporal evolution and life cycle of organised convection (e.g. Moncrieff et al., 2012; Tobin et al., 2013). As such, there is certainly scope for further in-depth evaluations to inform parameterisation development and improve global climate models. 
Acknowledgements. The work of M. D. Zelinka is supported by the Regional and Global Climate Modeling Program of the Office of Science at the US Department of Energy (DOE) and is performed under the auspices of the US DOE by Lawrence Livermore National Laboratory under contract DE-AC52-07NA27344. The National Center for Atmospheric Research is sponsored by the US National Science Foundation. P. Eriksson is supported by the Swedish National Space Board. The TMPA data were provided by the NASA/Goddard Space Flight Center's Mesoscale Atmospheric Processes Laboratory and PPS, which develop and compute the TMPA as a contribution to TRMM. In addition the CERES data were obtained from the NASA Langley Research Center Atmospheric Science Data Center. The authors would also like to acknowledge the NASA CloudSat project, which provided the CloudSat-CALIPSO data set used in this project. We would especially like to thank the anonymous reviewers, whose insights and critique of the paper contributed greatly to its quality.

Edited by: J. Quaas

\section{References}

Allan, R. P.: Combining satellite data and models to estimate cloud radiative effect at the surface and in the atmosphere, Meteor. Appl., 18, 324-333, doi:10.1002/met.285, 2011.

Arakawa, A.: The Cumulus Parameterization Problem: Past, Present, and Future, J. Climate, 17, 2493-2525, doi:10.1175/1520-0442(2004)017<2493:RATCPP>2.0.CO;2, 2004.

Austin, R. T., Heymsfield, A. J., and Stephens, G. L.: Retrieval of ice cloud microphysical parameters using the CloudSat millimeter-wave radar and temperature, J. Geophys. Res., 114, D00A23, doi:10.1029/2008JD010049, 2009.

Bechtold, P., Chaboureau, J. P., Beljaars, A., Betts, A. K., Köhler, M., Miller, M., and Redelsperger, J. L.: The simulation of the diurnal cycle of convective precipitation over land in a global model, Q. J. R. Meteorol. Soc., 130, 3119-3137, doi:10.1256/qj.03.103, 2004.

Bechtold, P., Köhler, M., Jung, T., Doblas-Reyes, F., Leutbecher, M., Rodwell, M. J., Vitart, F., and Balsamo, G.: Advances in simulating atmospheric variability with the ECMWF model: From synoptic to decadal time-scales, Q. J. R. Meteorol. Soc., 134, 1337-1351, doi:10.1002/qj.289, 2008.

Bechtold, P., Semane, N., Lopez, P., Chaboureau, J.-P., Beljaars, A., and Bormann, N.: Representing Equilibrium and Nonequilibrium Convection in Large-Scale Models, J. Atmos. Sci., 71, 734-753, doi:10.1175/JAS-D-13-0163.1, 2013.

Blackburn, M., Williamson, D. L., Nakajima, K., Ohfuchi, W., Takahashi, Y. O., Hayashi, Y.-Y., Nakamura, H., Ishiwatari, M., McGregor, J. L., Borth, H., Wirth, V., Frank, H., Bechtold, P., Wedi, N. P., Tomita, H., Satoh, M., Zhao, M., Held, I. M., Suarez, M. J., Lee, M.-I., Watanabe, M., Kimoto, M., Liu, Y., Wang, Z., Molod, A., Rajendran, K., Kitoh, A., and Stratton, R.: The AquaPlanet Experiment (APE): CONTROL SST simulation, J. Meteorol. Soc. Jpn., 91A, 17-55, doi:10.2151/jmsj.2013-A02, 2013.

Bodas-Salcedo, A., Webb, M. J., Bony, S., Chepfer, H., Dufresne, J. L., Klein, S. A., Zhang, Y., Marchand, R., Haynes, J. M., Pincus, R., and John, V. O.: COSP: Satellite simulation software for model assessment, B. Am. Meteorol. Soc., 92, 1023-1043, doi:10.1175/2011BAMS2856.1, 2011.

Buehler, S. A. and John, V. O.: A simple method to relate microwave radiances to upper tropospheric humidity, J. Geophys. Res., 110, D02110, doi:10.1029/2004JD005111, 2005.

Chen, W.-T., Woods, C. P., Li, J.-L. F., Waliser, D. E., Chern, J.D., Tao, W.-K., Jiang, J. H., and Tompkins, A. M.: Partitioning CloudSat ice water content for comparison with upper tropospheric ice in global atmospheric models, J. Geophys. Res. Atm., 116, D19206, doi:10.1029/2010JD015179, 2011.

Del Genio, A. D. and Wu, J.: The Role of Entrainment in the Diurnal Cycle of Continental Convection, J. Climate, 23, 2722-2738, doi:10.1175/2009JCLI3340.1, 2010.

Deng, M., Mace, G. G., Wang, Z., and Lawson, R. P.: Evaluation of several A-Train ice cloud retrieval products with in situ measurements collected during the SPARTICUS campaign, J. Appl. Meteor. Climatol., 52, 1014-1030, doi:10.1175/JAMC-D-12-054.1, 2012.

Emanuel, K. A.: A Scheme for Representing Cumulus Convection in Large-Scale Models, J. Atmos. Sci., 48, 2313-2329, doi:10.1175/1520-0469(1991)048<2313:ASFRCC>2.0.CO;2, 1991.

Eriksson, P., Rydberg, B., Johnston, M., Murtagh, D. P., Struthers, H., Ferrachat, S., and Lohmann, U.: Diurnal variations of humidity and ice water content in the tropical upper troposphere, Atmos. Chem. Phys., 10, 11519-11533, doi:10.5194/acp-1011519-2010, 2010.

Forbes, R. M., Tompkins, A. M., and Untch, A.: A new prognostic bulk microphysics scheme for the IFS, ECMWF Technical Memoranda 649, ECMWF, http://www.ecmwf.int/publications (last access: 4 April 2014), 2011.

Gehlot, S. and Quaas, J.: Convection-Climate Feedbacks in the ECHAM5 General Circulation Model: Evaluation of Cirrus Cloud Life Cycles with ISCCP Satellite Data from a Lagrangian Trajectory Perspective, J. Climate, 25, 5241-5259, doi:10.1175/JCLI-D-11-00345.1, 2012.

Gerard, L. and Geleyn, J.-F.: Evolution of a subgrid deep convection parametrization in a limited-area model with increasing resolution, Q. J. R. Meteorol. Soc., 131, 2293-2312, doi:10.1256/qj.04.72, 2005.

Gettelman, A., Morrison, H., and Ghan, S. J.: A new twomoment bulk stratiform cloud microphysics scheme in the community atmosphere model, Version 3 (CAM3). Part II: single-column and global results, J. Climate, 21, 3660-3679, doi:10.1175/2008JCLI2116.1, 2008.

Hazeleger, W., Severijns, C., Semmler, T., Stefãnescu, S., Yang, S., Wang, X., Wyser, K., Dutra, E., Baldasano, J. M., Bintanja, R., et al.: EC-Earth: A seamless earth system prediction approach in action, B. Am. Meteorol. Soc., 91, 1357-1363, doi:10.1175/2010BAMS2877.1, 2010.

Hendon, H. H. and Woodberry, K.: The diurnal cycle of tropical convection, J. Geophys. Res. Atm., 98, 16623-16637, doi:10.1029/93JD00525, 1993.

Houze, R. A.: Observed structure of mesoscale convective systems and implications for large-scale heating, Q. J. R. Meteorol. Soc., 115, 425-461, doi:10.1002/qj.49711548702, 1989.

Huffman, G. J., Bolvin, D. T., Nelkin, E. J., Wolff, D. B., Adler, R. F., Gu, G., Hong, Y., Bowman, K. P., and Stocker, E. F.: The TRMM Multisatellite Precipitation Analysis (TMPA): Quasi- 
Global, multiyear, combined-sensor precipitation estimates at fine scales, J. Hydrometeorol., 8, 38-55, doi:10.1175/JHM560.1, 2007.

Hurrell, J. W., Hack, J. J., Shea, D., Caron, J. M., and Rosinski, J.: A New Sea Surface Temperature and Sea Ice Boundary Dataset for Community Atmosphere Model, J. Climate, 21, 5145-5153, doi:10.1175/2008JCLI2292.1, 2008.

Johnston, M. S., Eriksson, P., Eliasson, S., Jones, C. G., Forbes, R. M., and Murtagh, D. P.: The representation of tropical upper tropospheric water in EC Earth V2, Clim. Dynam., 39, 27132731, doi:10.1007/s00382-012-1511-0, 2012.

Johnston, M. S., Eliasson, S., Eriksson, P., Forbes, R. M., Wyser, K., and Zelinka, M. D.: Diagnosing the average spatio-temporal impact of convective systems. Part 1: A methodology for evaluating climate models, Atmos. Chem. Phys., 13, 12043-12058, doi:10.5194/acp-13-12043-2013, 2013.

Lohmann, U. and Roeckner, E.: Design and performance of a new cloud microphysics scheme developed for the ECHAM general circulation model, Clim. Dynam., 12, 557-572, doi:10.1007/BF00207939, 1996.

Manabe, S. and Strickler, R. F.: Thermal equilibrium of the atmosphere with a convective adjustment, J. Atmos. Sci., 21, 361-385, doi:10.1175/1520-0469(1964)021<0361:TEOTAW>2.0.CO;2, 1964.

Manabe, S. and Wetherald, R. T.: Thermal Equilibrium of the Atmosphere with a Given Distribution of Relative Humidity, J. Atmos. Sci., 24, 241-259, doi:10.1175/15200469(1967)024<0241:TEOTAW>2.0.CO;2, 1967.

Moncrieff, M. W., Waliser, D. E., and Caughey, J.: Progress and direction in tropical convection research: YOTC International Science Symposium, B. Am. Meteorol. Soc., 93, 65-69, doi:10.1175/BAMS-D-11-00253.1, 2012.

Morrison, H. and Gettelman, A.: A new two-moment bulk stratiform cloud microphysics scheme in the community atmosphere model, version 3 (CAM3). Part I: description and numerical tests, J. Climate, 21, 3642-3659, doi:10.1175/2008JCLI2105.1, 2008.

Nam, C., Bony, S., Dufresne, J.-L., and Chepfer, H.: The "too few, too bright" tropical low-cloud problem in CMIP5 models, Geophys. Res. Lett., 39, L21801, doi:10.1029/2012GL053421, 2012.

Neale, R. B., Chen, C.-C., Gettelman, A., Lauritzen, P. H., Park, S., Williamson, D. L., Conley, A. J., Garcia, R., Kinnison, D., Lamarque, J.-F., Marsh, D., Mills, M., Smith, A. K., Tilmes, S., Vitt, F., Morrison, H., Cameron-Smith, P., Collins, W. D., Iacono, M. J., Easter, R. C., Ghan, S. J., Liu, X., Rasch, P. J., and Taylor, M. A.: Description of the NCAR Community Atmosphere Model (CAM 5.0), Tech. rep., National Center For Atmospheric Research, http://www.cesm.ucar.edu/models/cesm1.0/cam/docs/ description/ (last access: 11 November 2013), 2012.

Nesbitt, S. W. and Zipser, E. J.: The diurnal cycle of rainfall and convective intensity according to three years of TRMM measurements, J. Climate, 16, 1456-1475, doi:10.1175/1520-044216.10.1456, 2003.
Nordeng, T. E.: Extended versions of the convective parameterization scheme at ECMWF and their impact on the mean and transient activity of the model in the tropics, ECMWF Technical Memoranda 206, ECMWF, http://www.ecmwf.int/publications (last access: 4 April 2014), 1994.

Randall, D., Khairoutdinov, M., Arakawa, A., and Grabowski, W.: Breaking the Cloud Parameterization Deadlock, B. Am. Meteorol. Soc., 84, 1547-1564, doi:10.1175/BAMS-84-11-1547, 2003.

Stephens, G. L., L'Ecuyer, T., Forbes, R., Gettlemen, A., Golaz, J.C., Bodas-Salcedo, A., Suzuki, K., Gabriel, P., and Haynes, J.: Dreary state of precipitation in global models, J. Geophys. Res., 115, D24211, doi:10.1029/2010JD014532, 2010.

Stevens, B., Giorgetta, M., Esch, M., Mauritsen, T., Crueger, T., Rast, S., Salzmann, M., Schmidt, H., Bader, J., Block, K., Brokopf, R., Fast, I., Kinne, S., Kornblueh, L., Lohmann, U., Pincus, R., Reichler, T., and Roeckner, E.: Atmospheric component of the MPI-M Earth System Model: ECHAM6, J. Adv. Model. Earth Syst., 5, 146-172, doi:10.1002/jame.20015, 2013.

Sundqvist, H., Berge, E., and Kristjánsson, J. E.: Condensation and Cloud parameterization studies with a mesoscale numerical weather prediction model, Mon. Wea. Rev., 117, 1641-1657, doi:10.1175/1520-0493(1989)117<1641:CACPSW>2.0.CO;2, 1989.

Tiedtke, M.: A Comprehensive Mass Flux Scheme for $\mathrm{Cu}$ mulus Parameterization in Large-Scale Models, Mon. Weather Rev., 117, 1779-1800, doi:10.1175/15200493(1989)117<1779:ACMFSF>2.0.CO;2, 1989.

Tiedtke, M.: Representation of clouds in large-scale models, Mon. Weather Rev., 121, 3040-3061, doi:10.1175/15200493(1993)121<3040:ROCILS>2.0.CO;2, 1993.

Tobin, I., Bony, S., Holloway, C. E., Grandpeix, J.-Y., Sèze, G., Coppin, D., Woolnough, S. J., and Roca, R.: Does convective aggregation need to be represented in cumulus parameterizations?, J. Adv. Model. Earth Syst., 5, 692-703, doi:10.1002/jame.20047, 2013.

Tost, H., Jöckel, P., and Lelieveld, J.: Influence of different convection parameterisations in a GCM, Atmos. Chem. Phys., 6, 54755493, doi:10.5194/acp-6-5475-2006, 2006.

Waliser, D. E., Li, J.-L. F., Woods, C. P., Austin, R. T., Bacmeister, J., Chern, J., Genio, A. D., Jiang, J. H., Kuang, Z., Meng, H., Minnis, P., Platnick, S., Rossow, W. B., Stephens, G. L., SunMack, S., Tao, W.-K., Tompkins, A. M., Vane, D. G., Walker, C., and Wu, D.: Cloud ice: a climate model challenge with signs and expectations of progress, J. Geophys. Res., 114, D00A21, doi:10.1029/2008JD010015, 2009.

Zelinka, M. D. and Hartmann, D. L.: Response of humidity and clouds to tropical deep convection, J. Climate, 22, 2389-2404, doi:10.1175/2008JCLI2452.1, 2009.

Zhang, G. J. and McFarlane, N. A.: Sensitivity of climate simulations to the parameterization of cumulus convection in the Canadian climate centre general circulation model, Atmos.-Ocean, 33, 407-446, doi:10.1080/07055900.1995.9649539, 1995. 